Gerión. Revista de Historia Antigua

ISSN: 0213-0181

http://dx.doi.org/10.5209/geri.68596

\title{
Los hijos ilegítimos en la Hispania romana a través de las fuentes epigráficas $^{1}$
}

\author{
Francisco Cidoncha Redondo ${ }^{2}$
}

Recibido: 2 de febrero de 2019/ Aceptado: 30 de junio de 2019

Resumen. Al igual que en otras zonas del Imperio, nos encontramos con casos de hijos ilegítimos en el seno de la sociedad hispanorromana. Las fuentes epigráficas de Hispania aportan información sobre la descendencia nacida de uniones no reconocidas por el Derecho Romano. Hay una amplia variedad de casos que atestiguan su frecuencia y nos ofrecen algunas características de cómo sería la vida no solo de estos individuos, sino también la de sus progenitores.

Palabras claves: descendencia; ilegitimidad; spurius; filius; sociedad.

\section{[en] Illegitimate Children in Roman Hispania: An Epigraphical Study}

Abstract. As in other areas of the Roman Empire, there are some examples of illegitimate children in Hispania. The epigraphic sources provide us with some information about the offspring of non-recognized unions by the Roman Law. There is a variety of cases that attest their frequency. Moreover, they offer us some characteristics about what life would be like for these individuals and for their parents as well.

Keywords: Offspring; Illegitimacy; spurius; filius; Society.

Sumario: 1. Los hijos ilegítimos en la sociedad romana. 2. Los testimonios de hijos ilegítimos en la Hispania Romana. 2.1. La utilización de la expresión $S p(u r i) f(i l i u s,-a)$ en la filiación. 2.2. El uso de la expresión filius, -a naturalis. 2.3. El empleo de la onomástica. 2.3.1. Casos de padre e hijos con nomina diferentes y madre conocida. 2.3.2. Casos de padres e hijos con nomina diferentes y madre desconocida. 2.3.3. Casos de hijos que no tienen ni el nomen del padre ni el de la madre. 2.4. Los descendientes de los contubernia. 3. Conclusiones. 4. Anexo. 4.1. Utilización de la expresión $S p$ (uri) f(ilius, -a) en la filiación. 4.2. Casos en los que se documenta el uso de la expresión filius, -a naturalis. 4.3. Casos analizados por el empleo de la onomástica. 4.4. Casos en los que se documentan descendientes de contubernia. 5. Referencias bibliográficas.

Cómo citar: Cidoncha Redondo, F. (2020), Los hijos ilegítimos en la Hispania romana a través de las fuentes epigráficas, en Gerión 38/1, 307-332.

\footnotetext{
Trabajo enmarcado dentro del Proyecto del Programa Estatal de Generación de Conocimiento y Fortalecimiento Científico y Tecnológico del Sistema de I+D+i: "Marginación y visibilidad de la mujer en el Imperio romano: estudio de contrastes en los ámbitos políticos, jurídicos y religiosos" (PGC 2018-094169-B-I00). Asimismo, este estudio ha sido realizado en el marco del grupo de investigación: "Campo y Ciudad. Estructuras sociales, económicas e ideológicas en Andalucía y el Mundo Mediterráneo durante la Antigüedad" (HUM 441). Quiero agradecer la revisión de este artículo y la ayuda prestada por la Profesora Dr. ${ }^{a}$ D. ${ }^{a}$ Pilar Pavón Torrejón; no obstante, asumo cualquier error que permanezca en el mismo.

2 Universidad de Sevilla.

E-mail: fcidoncha@us.es
} 


\section{Los hijos ilegítimos en la sociedad romana}

El matrimonio romano puede ser definido como la unión duradera entre un hombre y una mujer que cumplía con una serie de requisitos como la posesión del ius connubii, la affectio maritalis o el honor matrimonii. ${ }^{3}$ La unión que contaba con esas características era reconocida desde el punto de vista jurídico. El objetivo de esta institución era, principalmente, la reproducción de una descendencia legítima, ya que esta representaba la continuación de la estirpe familiar y una seguridad para el futuro. ${ }^{4}$ Precisamente, una de las obligaciones de la esposa era concebir hijos, junto con su crianza y el cuidado del hogar. ${ }^{5}$

Todos aquellos filii que nacían fuera de un iustum matrimonium eran considerados ilegítimos por el Derecho Romano. ${ }^{6}$ Un hijo natural podía ser el fruto de uniones tales como un concubinatus, un contubernium o una mera relación sexual de carácter esporádico. Igualmente, entraban en este grupo todos aquellos nacidos de uniones incestuosas o adúlteras. ${ }^{7}$ Augusto promulgó una serie de leyes para luchar contra ello y para fomentar la vuelta a los valores romanos tradicionales; de esta manera, su legislación buscaba el restablecimiento de las buenas costumbres, favoreciendo las iustae nuptiae y la reproducción de vástagos legítimos. ${ }^{8}$ No obstante, las medidas diseñadas por este emperador, principalmente las prohibiciones matrimoniales en determinados casos, hicieron que se produjera un incremento de las uniones ilegítimas, junto con el aumento de la descendencia nacida en el seno de este tipo de relaciones. ${ }^{9}$

Las fuentes jurídicas romanas trataron el tema de la legitimidad de los hijos con frecuencia, sobre todo cuando existía una serie de intereses económicos de por medio. Aquellos que eran procreados en el seno de un iustum matrimonium ostentaban el estatus social que tenía su progenitor. ${ }^{10}$ Por lo tanto, el hijo sería un ciudadano romano siempre que su padre también lo fuera y mantuviera unas iustae nuptiae con una ciudadana romana, latina o peregrina que contara con el ius connubii. ${ }^{11}$ Cuando

Bonfante 1963, 256-257; Treggiari 1981a, 61; Friedl 1996, 46; Castán Pérez-Gómez 2000, 1464; Fayer 2005, 331 y 342; D’Ors 2006 [1968], 307; Valmaña-Ochaíta 2013, 139; Centlivres Challet 2013, 107; Cantarella 2015, 101. Algunas referencias al matrimonio también las podemos encontrar en D. 39.5 .31 pr., Pap. 12 resp.; D. 23.2.1, Mod. 1 reg.; D. 23.2.2, Paul. 35 ed.

4 Gardner 1997,35; Curchin 2000-2001, 538; Cenerini 2002, 13, 78; Treggiari 2002, 8; Astolfi 2006, 89; Salazar Revuelta 2013, 203; Centlivres Challet 2013, 23. En este sentido, la importancia del matrimonio la vemos en el discurso ofrecido por Q. Metelo Numídico para animar a los hombres a casarse, aunque también se enumeran algunos inconvenientes en él (Gell. 1.6.2A).

5 Flores Santamaría 1986, 217; Martínez López 1999, 144-147. La misma educación de las niñas estaba orientada al matrimonio y a la maternidad. Sobre ello, véase Álvaro Bernal 2018, 103-132.

6 Leonard 1900; Rodríguez Adrados 1986, 211; Evans Grubbs 1995, 294, 296, y 2002, 151; Valmaña-Ochaíta 2013, 146.

Gai. 1.64.

8 Numerosos investigadores han estudiado las leges Iulia de maritandis ordinibus y Papia Poppaea o tratado temas afines a ellas. Véase, por ejemplo, Raditsa 1980, 290-295; Galinsky 1981, 127; Rawson 1986a, 9-10; Astolfi 1996, 348; Spagnuolo Vigorita 2010 [1998], 110, 117, 134; Pérez Negre 1998, 142-143; Castán PérezGómez 2000, 1467; Treggiari 2002, 60; Evans Grubbs 2002, 83-84; Fayer 2005, 571; Valmaña-Ochaíta 2013, 142; Cantarella 2015, 41; 2016, 426-427.

9 Rawson 1986a, 10; McGinn 1991, 338.

10 Rawson 1966, 71-72.

11 Gai. 1.56; 1.76; Ulp. Tit. ex corp. 5.8. Sobre el ius connubii, véase Corbett 1930, 24-25, 28; Cherry 1990, 246; Arends Olsen 1999, 208. 
la unión de pareja no era legítima, sus descendientes adoptaban la condición social de la madre en el momento del nacimiento. ${ }^{12}$ De este modo, era libre aquel individuo que nacía del contubernium entre un servus y una ingenua. Para impedir que proliferaran este tipo de relaciones y para velar por los intereses de los propietarios de esclavos, se promulgó el senatusconsultum Claudianum de contubernio en el año 52 d.C. ${ }^{13}$ En él se dispuso que la mujer libre que cohabitaba con un esclavo debía contar con el permiso del dominus de este último para poder mantener la relación; ${ }^{14}$ cuando conseguía el visto bueno, ella pasaba a ser considerada liberta en el caso de que fuese ingenua, pero su descendencia era esclava y pertenecía al propietario del progenitor; ${ }^{15}$ por el contrario, si no contaba con la autorización del dominus de su pareja sentimental, podía caer en la esclavitud y perder su libertad. ${ }^{16}$ Posteriormente, el emperador Adriano dispuso que los hijos de estas uniones no debían ser esclavos, sino que eran libres siguiendo el estatus de su madre. ${ }^{17}$

La legitimidad de la descendencia también suponía que esta estuviese bajo la patria potestas. ${ }^{18}$ En el caso contrario, el progenitor no podía hacerse cargo de la custodia de los ilegítimos, estando estos en manos de la familia a la que pertenecía la madre. ${ }^{19}$ Por este motivo, se les debía asignar un tutor oficial, ya que la progenitora no tenía capacidad de ejercer la tutela sobre ellos. ${ }^{20} \mathrm{Al}$ mismo tiempo, como veremos en los ejemplos analizados, estos hijos heredaban el nomen de la familia materna, tanto si la madre era libre como si era esclava. Los padres que tenían descendencia libre e ilegítima podían adoptar a sus propios vástagos y, de esa manera, obtenían la patria potestas sobre ellos. ${ }^{21}$

Los filii naturales debían ser inscritos obligatoriamente en un registro público tras su alumbramiento, al igual que los legítimos, según dispusieron Marco Aurelio y Lucio Vero. ${ }^{22}$ Estos emperadores establecieron el plazo de treinta días para concederle un nombre al hijo y declarar su nacimiento ante las autoridades pertinentes, tanto en Roma como en las provincias. Igualmente, aceptaron que se pudiera admitir la declaración de nacimiento realizada a través de una carta de la madre, siempre que se comprobara su veracidad, sin ser necesario acudir a las autoridades oficiales. ${ }^{23}$ Antes de la llegada al poder de estos dos emperadores, los nacimientos de esta descendencia ilegítima no eran registrados. ${ }^{24}$

Los hijos naturales no podían ser nombrados herederos a través de la sucesión intestada, aunque los que eran ciudadanos romanos sí que podían recibir legados por

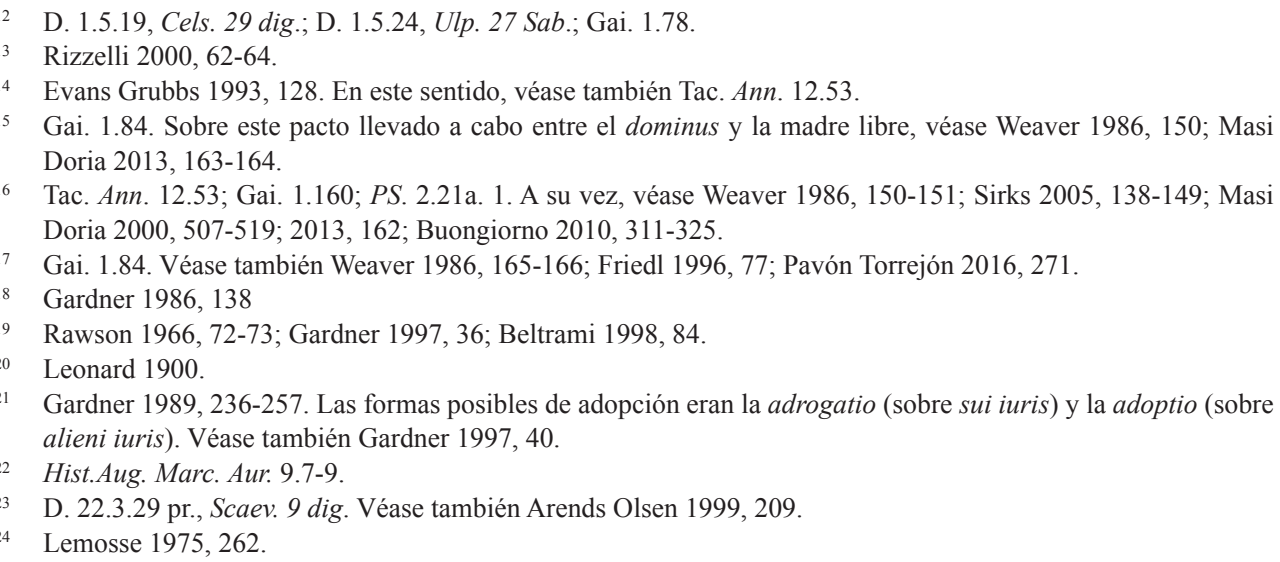


testamento. ${ }^{25}$ Los senadoconsultos Tertuliano y Orficiano nos aportan datos sobre las herencias de los mismos. Por un lado, Adriano dispuso en el senadoconsulto Tertuliano que las madres podían ser herederas de sus hijos ante la ausencia de otros familiares; ${ }^{26}$ por otro, Marco Aurelio estableció en el senadoconsulto Orficiano que ellos podían ser herederos intestados de sus progenitoras. ${ }^{27} \mathrm{Al}$ mismo tiempo, solamente los hermanos maternos, junto a sus madres, podrían reclamar la herencia de un spurius, ya que se consideraba que este no tenía un padre legítimo ni familia paterna. ${ }^{28}$

La ausencia de un progenitor legítimo en una sociedad tan patrilineal como la romana tendría una serie de consecuencias. ${ }^{29}$ La ilegitimidad podía constituir un hándicap para la carrera política de algunos individuos, ya que los hijos ilegítimos eran considerados "ciudadanos de segunda clase". ${ }^{30}$ Los emperadores Marco Aurelio y Lucio Vero establecieron en un rescripto que los hijos legítimos tenían preferencia sobre los naturales para formar parte del ordo decurionum. ${ }^{31}$ El jurista Ulpiano defendió que su acceso a este ordo no supondría una deshonra para el grupo. A pesar de su ilegitimidad, aquellos vástagos nacidos libres tendrían un estatus superior al de los esclavos liberados. ${ }^{32}$ La Lex Irnitana (91 d.C.) menciona la concesión de la ciudanía romana para las esposas y la descendencia de los magistrados locales siempre que existiesen unas iustae nuptiae. ${ }^{33}$ Por lo tanto, los hijos naturales de estos decuriones eran excluidos de poder disfrutar de ese privilegio. Lo mismo les ocurriría a sus compañeras sentimentales. No obstante, por lo general, la sociedad romana no miró con malos ojos a este tipo de descendencia, como sí ocurrió en épocas posteriores.

Las fuentes jurídicas romanas siguieron mostrando su interés por este tipo de progenie en los siguientes siglos. Entre las diferentes disposiciones relacionadas con este asunto, se establecieron tres formas de legitimación de los hijos naturales en el Derecho posclásico. La legitimatio per subsequens matrimonium estaba destinada a la descendencia de uniones ilegítimas que podían convertirse en iusta matrimonia; ${ }^{34}$ de esta manera, estos hijos pasaban a estar bajo la potestas paterna tras la celebración de las nupcias. La legitimatio per oblationum curiae era otro de los medios posibles para conseguir el reconocimiento jurídico de estos vástagos; ${ }^{35}$ estos eran legitimados con la condición de que pasaran a formar parte del grupo de los decuriones de una

\section{Robert 1986, 177}

26 D. 38.17.2 pr., Ulp. 13 Sab.; D. 38.17.2.1, Ulp. 13 Sab.; D. 38.17.2.4, Ulp. 13 Sab.; D. 38.17.2.6, Ulp. 13 Sab. También Biondi 1943, 139-140; Quadrato 1969, 362; Arends Olsen 1999, 206-207; Evans Grubbs 2002, 219; Fernández Vizcaíno 2011, 518-591; Cantarella 2016, 424; Pavón Torrejón 2016, 277-278.

27 Hist.Aug. Marc. Aur., 11.8; D. 38.17 .1 pr., Ulp. 12 Sab. Sobre ello, véase Gardner 1997, 48; Arends Olsen 1999 , 210; Cantarella 2016, 424; Pavón Torrejón 2016, 278.

28 D. 38.8.4, Ulp. 6 reg.

29 Beltrami 1998, 91-92.

30 Rawson 1966, 77.

31 D. 50.2.3.2, Ulp. 3 de off. proc.

32 Rawson 1986b, 178.

33 González Fernández 1986, 154.

34 Algunas referencias a la legitimatio per subsequens matrimonium y la descendencia las podemos encontrar en: C. 5.27.5.1, Imp. Zeno A. Sebastiano P. P. (a. 476); 5.27.6 pr., Imp. Anastasius A. Sergio P. P. (a. 517); 5.27.10 pr., Imp. Iustinianus A. Demostheni P. P. (a. 529); 5.27 .11 pr., 1-2, Imp. Iustinianus A. Iuliano P. P. (a. 530); 5.27.11.3, Imp. Iustinianus A. Demostheni P. P. (a. 529); Inst. 1.10.13; Nov. 19 pr., Imp. Iustinianus A. Iohanni P. P. (a. 536). Véase también Luchetti 1990, 173-288; Evans Grubbs 1995, 297.

35 Sobre la legitimatio per oblationum curiae, véase C. 5.27.4, Impp. Leo et Anthemius AA. Armasio P. P. (a. 470); 5.27.9 pr., 3, Imp. Iustinianus A. Mennae P. P. (a. 528); Nov. 89.2 pr., Imp. Iustinianus A. Iohanni P. P. (a. 539). 
ciudad, de este modo se obtenía una fuente de aprovisionamiento de ciudadanos para ocupar las magistraturas municipales en una época complicada debido a la escasez de candidatos para desempeñarlas. ${ }^{36}$ La tercera vía para conseguir la legitimación de la descendencia natural era per rescriptum principis, es decir, mediante la intervención del propio emperador. ${ }^{37}$ Estas disposiciones jurídicas, en la mayoría de los casos, no tenían la intención de apiadarse de la injusta situación de este tipo de descendencia; el objetivo de los emperadores fue, más bien, intentar luchar o erradicar algunas relaciones no reconocidas por el Derecho Romano como, por ejemplo, el concubinato. Algunos hijos naturales, nacidos de estas uniones, pudieron ser equiparados a los legítimos a través de las tres posibilidades; no obstante, no todos pudieron aprovecharse de estas oportunidades de reconocimiento jurídico, ya que muchos no cumplían los requisitos establecidos.

\section{Los testimonios de hijos ilegítimos en la Hispania Romana}

La primera referencia a los filii ilegítimos en la Hispania romana se encuentra en $A b$ Urbe condita, la obra de Tito Livio. ${ }^{38} \mathrm{El}$ escritor romano menciona la llegada de una delegación de vástagos de soldados romanos y de mujeres hispanas a Roma en el 170 a.C.; la finalidad de la misma era la legitimación de los descendientes de uniones desiguales que no disfrutaban del necesario ius connubii. ${ }^{39}$ Asimismo, solicitaban un lugar para vivir. Como solución, el Senado decretó la fundación de la Colonia Libertinorum Carteia, una colonia de estatuto latino situada en el actual término municipal de San Roque (Cádiz), para asentar a estos 4000 hombres. ${ }^{40}$ Este es un ejemplo de descendencia ilegítima nacida de las uniones de ciudadanos romanos con hispanas. Desconocemos cuál sería la condición jurídica de estas últimas, o la de sus hijos, debido a las diferentes interpretaciones que se han realizado del texto. ${ }^{41} \mathrm{R}$. López Melero aborda esta problemática y propone que, quizás, las madres eran captivae que habían sido repartidas entre los legionarios como botines de guerra. ${ }^{42} \mathrm{El}$ mismo nombre de la ciudad ya nos predispone a pensar que estamos ante una colonia de libertos. Por

\footnotetext{
Luchetti 1990, 65-172; Fayer 2005, 47.

Justiniano enumeró varios casos en los que se podía legitimar a estos hijos naturales: Nov. 74 pr., 1-2, Imp. Iustinianus Aug. Iohanni P. P. secundo e consule et patricio (a. 538). Véase también Nov. 89.9 pr., Imp. Iustinianus A. Iohanni P. P. secundo (a. 539). Véase Luchetti 1990, 289-321.

$38 \quad$ Liv. 43.3.1-4.

39 Sobre ello, véase Cherry 1990, 247-248.

40 Carteia fue la primera colonia latina fundada por los romanos fuera de la Península Itálica (Wulff Alonso 1989, 57).

41 López Melero 1991, 44.

42 López Melero 1991, 46-47. También García Moreno 1986, 216-217, cree que estas madres eran esclavas que se habían unido a los soldados romanos. Anteriormente, Saumagne 1962, 135-152, había defendido el origen servil de estos individuos que serían hijos de hombres romanos y mujeres esclavas. Sin embargo, otros consideran que los miembros de la delegación que viajó a Roma eran libres y peregrini (Fabre 1976, 420). Humbert 1976, 221-242, y Wulff Alonso 1989, 44-45, opinan que estas féminas eran libres, aunque su descendencia había experimentado lo que han denominado "esclavización formal", junto con una "manumisión ficticia" para insertarla en la sociedad romana. Rodríguez Oliva 2006, 125, ha defendido que los individuos de la legación tenían el estatus de libertos, habiendo sido manumitidos por $L$. Cannuleius como se indica en el texto de Livio; esto explicaría la existencia de referencias a personas que tienen el nomen de Cannuleius en zonas cercanas a Carteia (Rodríguez Oliva 2006, 123-157). Sobre el gentilicio Canuleius y la fundación de Carteia, véase también Pena 2014, 147-164.
} 
lo tanto, probablemente, ellas eran esclavas y habían transmitido el estatus servil a sus hijos.

Las fuentes epigráficas nos aportan una importante cantidad de referencias sobre los hijos naturales en la Hispania romana. Los ejemplos seleccionados se pueden clasificar por grupos en función de los datos que nos ofrecen para saber si los aludidos habían nacido en el seno de una unión no reconocida por el Derecho. No siempre es fácil clasificarlos porque, a veces, no indican su condición ilegítima en el texto; solamente hemos seleccionado aquellos casos en los que conocemos ambos progenitores o está clara su ilegitimidad. Los testimonios en los que solamente se alude a la madre, y no al padre, no han sido analizados, ya que no se puede comprobar la naturaleza de la descendencia al no contar con la suficiente información. Hay progenitores que tienen la misma nomenclatura y no por ello estaríamos siempre ante la unión de antiguos esclavos, ya que podrían ser miembros de una misma familia o, simplemente, podrían compartir el mismo gentilicium. En esas situaciones, los hijos legítimos adquirían el nomen paterno que coincidía también con el de la madre. Por lo tanto, los ejemplos en los que desconocemos quién era el padre no han sido seleccionados si no contamos con otros indicios como el empleo de las fórmulas Sp(uri) f(ilius, -a) o filius, - a naturalis.

\subsection{La utilización de la expresión $S p$ (uri) f(ilius, -a) en la filiación}

La expresión $S p$ (uri) f(ilius, -a), a veces, era empleada para designar a aquellos que habían sido procreados en el seno de una relación pasajera, de un matrimonium iniustum, de un contubernium o de un concubinatus. ${ }^{43}$ Ulpiano defiende que el término spurius hacía también referencia a aquel hijo que no tenía conocimiento de la identidad de su padre. ${ }^{44}$ Precisamente, en ninguno de los siguientes casos documentados aparecen referencias a la figura paterna de estos individuos.

Cornelia Homulla fue la destinataria, entre otros, de un monumento funerario en Barcino. ${ }^{45}$ La expresión Sp (uri) fil(ia) aparece incluida en su onomástica. No es la única, ya que en la inscripción se nombran a dos individuos más con la misma filiación: Cornelius Sp(uri)f(ilius) (H)ispanus y Cornelius Sp(uri)f(ilius) Marcellus. Estos últimos serían, con mucha probabilidad, hermanos de Cornelia Homulla y todos habrían nacido de una unión ilegítima. El encargado de la construcción de la tumba fue L. Valerius Rufinus, el contubernalis de la propia Homulla. El contubernium de ambos no habría tenido descendencia al establecerse el deseo de que ningún heredero se enterrase en ese lugar. No obstante, también esta voluntad podría ser el resultado de unas malas relaciones familiares o de una falta de espacio en la misma sepultura.

Q. Cornelius Sp(uri) f(ilius) Sec[undus] fue el dedicante de una inscripción funeraria para sí mismo y para toda su familia en Barcino. ${ }^{46}$ Él era oriundo

43 Lécrivan 1887; también Beltrami 1998, 86-90. A veces, Spurius fue un gentilicium e, incluso, un praenomen o un cognomen (Kajanto 1965, 40, 73, 298; Solin - Salomies 1988, 175, 407). Aquí hemos tenido en cuenta aquellos ejemplos en los que aparece la expresión $S p($ uri) f(ilius, -a), ya que el hecho de portar Spurius como nomen no indica que el nacimiento sea ilegítimo. Asimismo, no se ha detectado en Hispania el uso de Spurius como cognomen.

$44 \quad$ Ulp. Tit. ex corp 4.2.

45 IRC IV, 221 (=HEp 7, 1997, 187). Testimonio $\mathrm{n}^{\circ} 1$ del anexo.

46 IRC IV, 59 (=AE 1966, $207=A E$ 1993, $1746=H E p ~ 7,1997,208=A E$ 2008, $761=$ Navarro Caballero 2017, 466). Testimonio $n^{\circ} 2$ del anexo. 
de Carthago Magna, aunque había dejado esta ciudad por algún motivo que desconocemos. Cor(nelia) Sp(uri) f(ilia) Tertull(a) era su hermana y aparece en el mismo epitafio junto a la madre de ambos, Corne[lia] Quarta. No sabemos por qué tanto Sec[undus] como Tertull(a) eran considerados hijos ilegítimos. La naturaleza de la unión de sus progenitores habría provocado que ellos tuviesen dicha condición. Sin embargo, el nombre del padre no aparece entre los familiares mencionados en el texto. Según reza en la inscripción, ambos hermanos se asentaron en Barcino y tuvieron descendencia allí. Por un lado, Q. Cornerlius Sec[undus] estuvo unido en un iustum matrimonium con Gem(i)na Q[uar]ta y tuvo cuatro hijos: Cornelia Tertull[a], Corn(elia) Quartull(a), Cor(nelia) Dubit[ata] y Q. Corn(elius) Seran(us). Este último desempeñó varios cargos en la administración municipal. Por otro lado, sabemos que la hermana del dedicante tuvo un hijo llamado L. Mae[vius] Rogatus. Tampoco se incluye en el epígrafe el nombre del padre de este y marido de Cor(nelia) Sp (uri) f(ilia) Tertull(a). A pesar de ello, podemos asegurar que Rogatus había nacido en un matrimonium iustum según se puede observar en su onomástica.

Un epígrafe de Augusta Emerita, costeado por una liberta llamada Servilia Fausta, recoge los nombres de cuatro individuos enterrados en el mismo lugar. ${ }^{47}$ Todos ellos eran miembros de la familia de los Servilii, o estaban relacionados con ellos, aunque no se indican los vínculos que les unían. El cabeza de familia sería M. Servilius, un ingenuus que pertenecía a la tribu Papiria y que es el primero mencionado en el texto. Una liberta llamada Pompeia Helena, posiblemente su compañera sentimental, aparece tras él en el epígrafe. A continuación, se nombra a M. Servilius Tertius, que podría ser un hijo de los anteriores. Por último, se incluye también un individuo llamado $M$. Servilius Sp(uri) f(ilius) Pollio. De este sí que conocemos su condición de ilegítimo a través de la filiación. Posiblemente, Pollio era un hijo que había nacido de la unión no reconocida por el Derecho Romano entre M. Servilius y la liberta Pompeia Helena. Algún motivo que desconocemos podría haber impedido que ambos pudiesen formar un matrimonium iustum, lo cual habría afectado a su descendencia.

Otra inscripción procedente de Penelles, en la actual provincia de Lérida, alude a una mujer llamada Atilia Spuri f(ilia) Lucilla. ${ }^{48}$ Ella podría ser una hija ilegítima, aunque no tenemos datos sobre sus progenitores. Solamente sabemos que $M$. Antonius Inachus fue su maritus y el encargado de costear este epígrafe.

\subsection{EI uso de la expresión filius, -a naturalis}

La expresión filius o filia naturalis también fue utilizada para designar a la descendencia ilegítima. Su uso está atestiguado en algunos epígrafes procedentes de la Península Ibérica.

M. Septicius Martialis fue un filius naturalis mencionado en un epitafio de Corduba:49 falleció con tan solo diez años y siete meses de edad, siendo recordado por sus padres: M. Septicius y Sabi[n]a. ${ }^{50}$ El progenitor era un ingenuus que pertenecía

\footnotetext{
ERAE 368. Testimonio $\mathrm{n}^{\circ} 3$ del anexo.

CIL II 4457 (=IRC II, $18=$ HEp 6, 1996, $635=A E$ 1997, 924). Testimonio $\mathrm{n}^{\circ} 4$ del anexo.

CIL II $2 / 7,288$ (=AE 1987, 505=HEp 2, 1990, $324=H E p ~ 5,1995,319)$. Testimonio $\mathrm{n}^{\circ} 5$ del anexo.

Tanto las fuentes escritas como las arqueológicas demuestran que la mortalidad infantil era bastante elevada en época romana. Un ejemplo de ello lo podemos ver en los tres epigrammata que el poeta Marcial dedicó a Erotion, una pequeña serva que había fallecido a los seis años (Mart. 5.34, 5.37, 10.61). Según D’Ambra 2007,
} 
a la tribu Papiria y desempeñaba el cargo de aquilifer en el ejército romano. ${ }^{51} \mathrm{El}$ pequeño difunto era liberto, probablemente, de su propio padre. Su madre tenía un origen servil, aunque desconocemos si ya había sido manumitida en el momento de realizarse el texto, pues no se menciona su condición de liberta y solamente aparece su cognomen, por lo que podría seguir siendo una esclava cuando se produjo la muerte de su hijo. Sí que se alude a su condición de contubernalis de M. Septicius. No solo el estatus servil había impedido unas iustae nuptiae entre ellos, sino que la prohibición de matrimonio para los soldados durante sus años de servicio había hecho imposible una unión legítima. ${ }^{52}$ Por último, el epitafio incluía la voluntad del dedicante de que los herederos no se enterrasen en el mismo monumento funerario.

C. Atenius Acutus dispuso en su testamento el deseo de realizar un monumento funerario para sí mismo y para dos mujeres en Hispalis. ${ }^{53}$ Tertia, una de ellas, fue calificada como su filia naturalis. No se indica cuál era la vinculación de la otra fémina, Optata. Puede ser que fuera la esposa del dedicante y madre de Tertia. Lo que sí podemos afirmar es que la hija había nacido siendo ilegítima, aunque desconocemos cuál fue el motivo que impidió que sus progenitores mantuvieran un iustum matrimonium. En otro epitafio del conventus Tarraconensis se menciona el fallecimiento de una joven llamada Otacil(ia) Seran(a) a los dieciocho años de edad. ${ }^{54}$ Era la hija de Otacil(ius) Seranus y de Otac(ilia) Chrysopolis. La forma de aludir a la difunta en el texto cambia en función de quién es el dedicante: el padre se refiere a ella como su filia naturalis, mientras que la madre la califica solamente como su filia, sin aludir a su condición de ilegítima. Este ejemplo ilustra el hecho de que la ilegitimidad afectaba, principalmente, a las relaciones paterno-filiales. Los tres individuos tienen el mismo gentilicium, por lo que podemos estar ante una familia de origen servil, aunque también podría tratarse de la unión de un hombre libre y una mujer esclava. ${ }^{55}$ No obstante, todos ellos eran libres en el momento en el que se mandó realizar el monumento. Al mismo tiempo, la hija comparte el cognomen con su padre.

\subsection{El empleo de la onomástica}

El uso de la onomástica nos aporta bastantes datos sobre la condición de aquellos hijos ilegítimos que no aparecen aludidos en la epigrafía como $S p$ (urii) f(ilii) o como filii naturales. En este grupo se incluyen individuos ingenui, liberti y servi.

66, la mitad de los niños morían en los diez primeros años de vida. Véase también Rawson 1986a, 9; Garnsey 1991, 51; Curchin 2000-2001, 539; McWilliam 2001, 75.

51 Probablemente, este aquilifer formaría parte de la legio X Gemina y habría llegado a Corduba procedente de Astigi (Ordóñez Agulla 1988, 48). Otros consideran que Augusta Emerita era el lugar de origen de M. Septicius (Marcos Pous 1987, 480; Perea Yébenes 1993, 299).

52 Meyer 1895 [1966], 25; Campbell 1978, 153-154; Friedl 1996, 230; Wells 1998, 180-190; Arends Olsen 1999, 186; Castán Pérez-Gómez 2000, 1465; Speidel 2013, 205.

53 CIL II 1213 (=CILA 2, 103). Testimonio $\mathrm{n}^{\circ} 6$ del anexo.

$54 C I L \mathrm{II}^{2} / 14,266(=I R P V 49=A E 1984,603)$. Testimonio $\mathrm{n}^{\circ} 7 \mathrm{del}$ anexo.

55 Algunos investigadores se decantan por la posibilidad de que tanto la madre como la hija fuesen libertas del padre. Véase Alfödy 1984, 236; Curchin 2000, 127. 


\subsubsection{Casos de padre e hijos con nomina diferentes y madre conocida}

Comenzaremos mencionando aquellos testimonios que se refieren a hijos ilegítimos que portan el nomen materno y no el paterno. Hay que tener precaución cuando estemos ante ejemplos de este tipo porque, a veces, era costumbre adoptar el gentilicium materno entre la aristocracia romana. Normalmente, esto ocurría en los casos en los que la familia de la madre tenía más prestigio o poder que la paterna. ${ }^{56}$ Sin embargo, esa situación no se cumplía en los siguientes casos analizados.

Allia Avita fue la hija que nació de la unión formada por Valerius Ursacius y Allia [Ruf]ina. ${ }^{57}$ Fue recordada en un epitafio de Conimbriga tras su muerte a los veintitrés años. Como podemos observar, tenía el mismo gentilicium que su madre y no el paterno. Otro ejemplo similar lo encontramos en la familia formada por M. Publicius Felix y Asellia Hygia en Augusta Emerita. ${ }^{58}$ Fue la hija de ambos, Asellia [Cl]audia, la que mandó realizar un bello monumento funerario a sus padres siguiendo los expresos deseos de los mismos..$^{59} \mathrm{El}$ nomen paterno se asocia, normalmente, con libertos públicos y su cognomen es atestiguado en el ámbito servil; ${ }^{60}$ también el cognomen de la madre puede indicar un pasado como esclava. ${ }^{61}$ La hija, como ya se ha indicado, portaba el gentilicium materno y no el paterno como era lo adecuado en una unión legítima, por lo que sus padres no mantenían una relación reconocida por el Derecho Romano al menos en el momento de su nacimiento. No sabemos si con el tiempo pudieron legitimar su unión. Lo que sí está claro es que Felix era esclavo cuando su hija vino al mundo e Hygia era, probablemente, una liberta o una ingenua que pertenecía a una familia de libertos. La madre habría contado con la autorización para poder mantener una unión sentimental con el esclavo. La inscripción puede ser datada en la segunda mitad del siglo II d.C., por lo que Asellia [Cl] audia habría nacido libre siguiendo lo dispuesto en la reforma que el emperador Adriano realizó del conocido senatusconsultum Claudianum de contubernio. Esa es la hipótesis que consideramos más acertada, pero existen otras. Entre otras alternativas, J. Edmondson plantea la posibilidad de que estuviésemos ante un "matrimonio mixto" entre un civis Romanus y una Latina Iuniana, por lo que la descendencia seguiría la condición jurídica materna y adquiriría su nombre. ${ }^{62}$

Las madres y los hijos comparten, con mucha frecuencia, la onomástica en los casos estudiados. Como ya hemos observado, la descendencia no legítima solía portar el nomen materno y no el paterno. ${ }^{63}$ En este sentido, la inscripción funeraria de Plotia Sartunina, localizada en Tarraco, nos aporta información al respecto. ${ }^{64}$ La difunta había fallecido a los veintiocho años y fue recordada por su marido,

56 A veces, incluso, la descendencia porta los nomina tanto del padre como de la madre. Véase, por ejemplo, Solin $1973,406$.

CLEH 78 (=AE 1975, 483). Testimonio $\mathrm{n}^{\circ} 8 \mathrm{del}$ anexo.

HEp 2, 1990, 37. Testimonio $\mathrm{n}^{\circ} 9$ del anexo.

Un estudio pormenorizado fue realizado por Edmondson - Nogales Basarrate - Trillmich 2001, 153-156.

Kajanto 1965, 134, 272-273.

Solin 1982, 361-362.

Edmondson 2001, 81.

Podemos hacer referencia a casos como el de Valerius Melippus y su hija Caelia Saturnina en Barcino (CIL II $6178=I R C$ IV, 219. Testimonio no 12 del anexo) o el de Sergius Ursio y su hijo Baebius Senecianus en Saguntum $\left(C I L \mathrm{II}^{2} / 14,649=\right.$ CIL II $3972=$ ELST 305. Testimonio $\mathrm{n}^{\circ} 13$ del anexo).

$64 \quad C I L \mathrm{II}^{2} / 14,1638$ (=RIT 639). Testimonio $\mathrm{n}^{\circ} 10$ del anexo. 
Aelius Melpon, y por su hija, Plotia Iucunda. Podemos pensar que Iucunda había nacido de un primer matrimonio de la mujer recordada en el epitafio. Sin embargo, el hecho de indicar los años de convivencia entre Aelius Melpon y Plotia Saturnina hace que se descarte esta posibilidad. De este modo, los progenitores de Plotia Iucunda habían comenzado su relación cuando su madre tenía dieciséis años, dato que refuerza aún más la afirmación de que Iucunda era hija de ambos. No obstante, la relación carecía de validez jurídica a pesar de que se empleó el término coniux y no otros vocablos más acordes como concubina o contubernalis. Esa era la causa que había propiciado que la hija tuviera el nomen materno en su onomástica. La edad de la misma no era muy elevada, ya que su madre murió bastante joven, motivo que no impidió que fuera la dedicante del monumento funerario junto a su padre.

Se han clasificado otros casos similares al anterior. Un epígrafe de Barcino nos informa de la unión formada por Aelius Cestinus y Numisia Ursula, cuyo hijo fue llamado Numisius Cestus. ${ }^{65}$ A pesar de su ilegitimidad, la paternidad está asegurada por la utilización de un cognomen con la misma raíz tanto en el padre como en el hijo. Sin embargo, ellos no comparten el gentilicium. Hay otros ejemplos de padres y descendientes naturales que portan el mismo cognomen. En la Baetica, sabemos que Fabia Prisca fue una hija que nació de la relación de C. Geminius Priscus y Fabia Cadilla. ${ }^{66}$ También se manifiesta la misma tendencia entre Aelius Primianus y su hijo Caec(ilius) Prim[i]anus. ${ }^{67}$ Ambos fueron recordados en un epitafio de Barcino por Caecil(ia) Daphinis, su esposa y su madre, respectivamente. El epitafio de $L$. Annius Abascantus y de su hija Terentia Annia en Asturica Augusta nos presenta otro caso diferente. ${ }^{68}$ El nomen del padre es utilizado como cognomen por su hija. Sin embargo, ella tiene el gentilicium de su madre, Terentia Ap [ra].

M(inicius) Chrestu(s) fue un hijo natural nacido del contubernium formado por sus padres, Vitalis y Minicia Chreste, en Toletum. ${ }^{69}$ La ausencia de nomen en la onomástica del padre indica que, probablemente, estamos ante un servus. Esta hipótesis puede ser confirmada por el hecho de que fue el único individuo del texto que solamente fue nombrado con su cognomen. Por su parte, madre e hijo comparten el mismo gentilicium. Ella tuvo origen servil, atestiguado por su cognomen griego, aunque ya había conseguido la libertad cuando se realizó esta inscripción. ${ }^{70}$ El hijo pudo haber nacido en la esclavitud y también habría sido manumitido posteriormente. Otra posibilidad es que hubiese venido al mundo en el seno de una relación entre un servus y una liberta, lo cual habría influido en la adopción del nomen materno.

Un caso similar al anterior lo protagoniza L. La[be]rius Antigonus, descendiente ilegítimo nacido de la unión entre L. Maecius Scepticus y Laberia Daphne en Augusta Emerita. ${ }^{71}$ Esta relación tuvo una duración de cincuenta y dos años y, con mucha probabilidad, habría comenzado cuando uno de ellos, o los dos, eran esclavos. De esta manera, L. La[be]rius Antigonus habría nacido esclavo en el caso de que su madre también lo fuera, o libre si ella ya había sido manumitida antes del parto.

\footnotetext{
$C I L$ II 6172 (=IRC IV, $196=H E p$ 5, 1995, 128). Testimonio $\mathrm{n}^{\circ} 11$ del anexo.

CIL II 971 (=ERBC $209=H E p$ 7, 1997, 1152). Testimonio n ${ }^{\circ} 14$ del anexo.

$C I L$ II 4558 (=IRC IV, 141). Testimonio $\mathrm{n}^{\circ} 15$ del anexo.

IRPLe $94\left(=E R P L e 114=\right.$ ENAR 49). Testimonio $\mathrm{n}^{\circ} 16$ del anexo.

CIL II 3085 (=IRPTo $21=$ HEp 2, 1990, 680). Testimonio $\mathrm{n}^{\circ} 17$ del anexo.

Solin 1982, 931-934.

HEp 7, 1997, 121 (=AE 1999, 875). Testimonio $\mathrm{n}^{\circ} 18$ del anexo.
} 
Todos fueron mencionados en un epitafio familiar junto con una mujer llamada Cornelia Valentina que bien pudo haber sido la esposa de Antigonus, aunque no se indicó el vínculo que existía entre ellos. Además, su nombre se colocó en la moldura de la placa de mármol, por lo que no estaba previsto que fuera sepultada en ese lugar en un primer momento.

Un pedestal de Tarraco fue dedicado a Domitia Quartilla por varios miembros de su familia. ${ }^{72}$ M. Iulius Paris y Domitia Musa, sus padres, son los primeros que aparecen en el texto en calidad de dedicantes. Como podemos observar, madre e hija compartían el mismo nomen. L. [Do]mit(ius) Theseus, el hijo de la homenajeada, también quiso formar parte del grupo de personas que recordaron a su madre. Vemos, igualmente, cómo él tenía el mismo gentilicium que su progenitora. Estos individuos tenían un pasado servil, como parecen evidenciar sus cognomina griegos. ${ }^{73}$ Domitia Quartilla había nacido antes de la concesión de la libertad a su madre y las dos habían sido propiedad de la familia de los Domitii. Lo mismo había ocurrido una generación posterior con Theseus, del cual no sabemos quién fue su padre. Por lo tanto, estamos ante una familia de libertos enriquecidos que homenajearon a uno de sus miembros con una escultura y su pedestal.

$P$. Volumnius Vitalis aparece dedicando una inscripción funeraria a su padre fallecido en Corduba ${ }^{74}$ El difunto era un murmillus llamado Probus, que había nacido en Germania y había encontrado la muerte en esta ciudad hispana. Su compañera sentimental, Volumnia Spera[ta], fue la otra dedicante del epitafio junto a su hijo. Ella sería de condición libre, aunque no podemos afirmar si era ingenua o liberta. $P$. Volumnius Vitalis, por su parte, tenía el gentilicium materno por lo que, seguramente, fue el fruto de la unión ilegítima de sus progenitores. El gladiador pudo haber sido un servus, ya que tenía un nomen unicum, aunque tampoco puede descartarse que este fuera su nombre "artístico". ${ }^{75}$

En Caesarobriga, una joven llamada Flavia Rufina fue recordada en un epitafio tras su fallecimiento con veinticuatro años. ${ }^{76}$ Los dedicantes del monumento funerario fueron sus padres, C. Rustenus Decianus y Honorina. Padre e hija no compartían el mismo nomen y no sabemos cuál era el de su madre, ya que solo se menciona el cognomen. El hecho de que no aparezca un maritus entre los dedicantes puede indicar, probablemente, que la difunta era soltera.

En Lancia Oppidana, Cl(audius) Severus dedicó un epitafio conjunto a sus progenitores: Caius Caenonisf(ilius) y Cl(audia) Casina ${ }^{77}$ La unión entre un hombre peregrinus y una mujer romana dio lugar a la ilegitimidad de su descendencia, ya que no había el ius connubii necesario para la formación de un iustum matrimonium. ${ }^{78}$

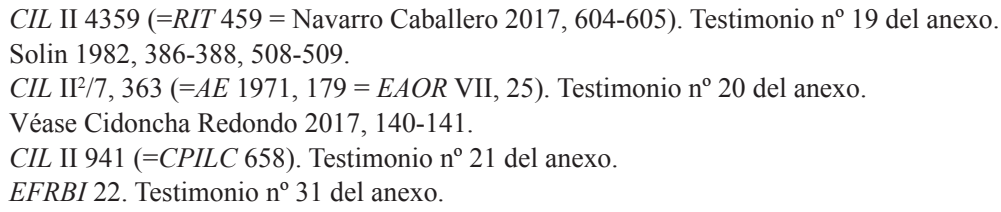
abordaba la gran variedad de situaciones posibles en relación con las uniones mixtas entre ciudadanos romani, peregrini, latini, etc. Véase, por ejemplo, Gai. 1.77-81; Ulp. Tit. ex corp. 5.9. La finalidad de este interés era establecer cómo se debía actuar ante cada uno de los casos. P. Pavón Torrejón 2016, 270-271, ha señalado que este control de los diferentes tipos de relaciones de pareja posibles tenía el objetivo de evitar problemas sobre las personas que podían acceder a la ciudadanía romana. No obstante, algunos dilemas se solucionaron tras la extensión de la ciudadanía romana a todos los habitantes del Imperio de la mano de Caracalla a principios 
De esta manera, el hijo no llevó la onomástica indígena típica de nombre único y filiación, sino que tenía el mismo gentilicium que su madre y un cognomen. La cronología de la inscripción se sitúa en torno a la segunda mitad del siglo I d.C. Posteriormente, ya en el siglo II d.C., un senadoconsulto de Adriano dispuso que la descendencia nacida de la unión entre una ciudadana romana y un peregrinus, aunque no disfrutara de connubium, sería legítima. ${ }^{79}$

\subsubsection{Casos de padres e hijos con nomina diferentes y madre desconocida}

En ocasiones, no contamos con referencias a las madres de estos individuos, pero sí que se menciona a sus padres. El hecho de que los progenitores y sus hijos no compartan la misma onomástica puede ser interpretado como un indicio de ilegitimidad. C. Iulius Severus nació de la unión de un soldado romano llamado $L$. Valerius Severus y una mujer de la que desconocemos su identidad.$^{80}$ Ellos fueron nombrados en una inscripción funeraria colocada en Tarraco. El texto nos revela que el progenitor ya era un veterano de la legio VII Gemina Felix en el momento de su muerte, pero había estado aún en activo cuando nació su hijo, de ahí la condición ilegítima del mismo.

Hay otros testimonios de padres e hijos con nomina diferentes, en los que desconocemos la identidad de sus madres. Una inscripción funeraria de Tarraco hace referencia al fallecimiento de L. Popilius Prunicus a los veinticinco años. ${ }^{81}$ Fue su padre, C. Cornelius Primigenius, quien honró su memoria con este epitafio. La ausencia de la madre pudo deberse a su fallecimiento en un momento anterior a la construcción de la sepultura. De Pallantia también conocemos el caso de L. Cassius Reb(urrus), el hijo de Cl(audius) Reburrus. ${ }^{82}$ Otro ejemplo similar es el de L. Iul(ius) Herennianus que dedicó un epitafio a su padre, L. Clodius Barbarius, fallecido a los cincuenta años en Pax Iulia ${ }^{83}$ Padre e hijo tenían una onomástica diferente y tampoco contamos con información sobre la madre. ${ }^{84}$

\subsubsection{Casos de hijos que no tienen ni el nomen del padre ni el de la madre}

A veces, los hijos no portan ni el nomen paterno ni el materno. Un ejemplo de ello lo encontramos en una inscripción funeraria de Hispania Citerior colocada por Ant(onius) Modestus a sus padres, M[a]rcius Faus(tus) y Cantia Karia ${ }^{85}$ Lo mismo ocurre con Aurelia Anna y sus progenitores, Iulia Alba y Cl(audius) Graci[lis]. ${ }^{86} \mathrm{La}$ hija honró la memoria de sus padres difuntos con un epitafio para ambos en Augusta Emerita. Según el texto, Graci[lis] era soldado de la leg(io) VII G(emina) F(elix),

del siglo III. Sobre este tipo de uniones y la Constitutio Antoniniana, léase Arends Olsen 1999, 210; Herreros González - Santapau Pastor 2005, 92; González Fernández - Fernández Ardanaz 2010, 164-165, 171-174.

Gai. 1.77 .

CIL II $4172\left(=\right.$ RIT $225=C I L$ II $\left.^{2} / 14,1086\right)$. Testimonio $\mathrm{n}^{\circ} 28$ del anexo.

$C I L \mathrm{II}^{2} / 14,1645$ (=RIT 645). Testimonio $\mathrm{n}^{\circ} 29$ del anexo

CIL II 5769 (=EE VIII, 2, p. $409=I R P P$ 85). Testimonio $\mathrm{n}^{\circ} 32$ del anexo.

IRCP 254. Testimonio $\mathrm{n}^{\mathrm{o}} 30 \mathrm{del}$ anexo.

${ }^{84}$ Hay otros ejemplos similares en la sociedad hispanorromana: CIL II 5892 (=IRET $\left.137=I R E T^{2} 173\right)$; CILA 2, 195; CIL II 3573 (=IRILAD 108); CIL II 2752 (=HEp 4, 1994 629); IRPTo 193; AE 1985, 512.

CIRG I, 54 (=HEp 4, 1994, 352). Testimonio $\mathrm{n}^{\circ} 22$ del anexo.

HEp 19, 2010, 51 (=HEp 20, 2011, $15=$ = AE 2010, 674). Testimonio $\mathrm{n}^{\mathrm{o}} 23$ del anexo. 
por lo que no pudo haber contraído un iustum matrimonium en sus años de servicio. ${ }^{87}$ A pesar de ello, los legionarios mantenían relaciones esporádicas o uniones estables durante ese tiempo. El concubinato era una de las opciones posibles para estos soldados ${ }^{88}$ Algunas de estas relaciones se convirtieron en uniones legítimas tras producirse el licenciamiento, siempre que cumpliesen los requisitos para contraer unas iustae nuptiae. En el caso analizado, la hija ilegítima tampoco comparte el nomen materno. Una hipótesis podría ser que la madre habría sido una serva y su hija habría nacido en la esclavitud; posteriormente, ambas mujeres serían manumitidas por diferentes domini y ese sería el motivo para explicar que no tenían el mismo nomen.

Fonteia Melit[ine] fue otra hija que tenía una nomenclatura diferente a la de sus padres. Ella recordó a su padre fallecido, Flavius Onesimus, con una inscripción funeraria en Tarraco. ${ }^{89}$ También su madre, Flavia Cleopa[tra], participó en la dedicación de la lápida a su esposo. Los progenitores de Melit[ine] eran, probablemente, libertos de la misma familia, ya que compartían el nomen. Sin embargo, ella no tenía el gentilicium que sus progenitores. Esta diferenciación pudo deberse a que Melit [ine] era también una liberta y fue manumitida por otro dominus.

Hay que tener precaución en algunos casos que se localizan en la Hispania romana. A veces, padres e hijos no tienen los mismos nomina por otros motivos y no necesariamente son descendientes ilegítimos. Buen ejemplo de esta circunstancia es un epitafio de Augusta Emerita..$^{90}$ P. Iul(ius) Hermetion e Iulia Pitne dedicaron un monumento funerario a su hijo, Q. Baebius Florus, fallecido a los veinte años. Posiblemente, los progenitores eran libertos de la familia de los Iulii; su hijo, sin embargo, nació ya en la libertad porque pertenece a la tribu Galeria y se indicó su origo Pacensis. ¿Por qué Florus no tenía el nomen Iulius? Quizás Hermetion no era su padre biológico, sino su padrastro y el segundo marido de Pitne..$^{91}$ La utilización del término pater para referirse al dedicante del epígrafe puede sugerir que él actuó como un verdadero padre para el difunto. Posiblemente, el progenitor biológico de Florus perteneció a la familia de los Baebii y pudo haber muerto cuando su hijo era pequeño o, directamente, no se hizo cargo de él.

Caecilius Polychronius y Aurelia Primitiva tuvieron que afrontar la desagradable situación de enterrar a su hija, Valeria Modestina.$^{92}$ La difunta, que contaba con veinticuatro años cuando murió, fue recordada en un epígrafe de Tarraco. Vemos, de nuevo, a una hija que no comparte la onomástica de sus progenitores. Lo mismo les ocurrió a Turan(i)us Primitivus y Liberia Stercusia con su vástago, Valerius Rufinus, que falleció con veintitrés años en Conimbriga ${ }^{93}$ Igualmente, M. Ulpius Heuretus,

\footnotetext{
Sobre la prohibición matrimonial de los legionarios en servicio, véase nota ${ }^{\circ} 52$.

Rawson 1974, 279.

$C I L \mathrm{II}^{2} / 14,1559\left(=\right.$ RIT 580). Testimonio $\mathrm{n}^{\circ} 33$ del anexo.

$C I L$ II 516 (=EE VIII, 2, p. $362=E R A E$ 189). Testimonio $\mathrm{n}^{\circ} 24$ del anexo.

Curchin 2000, 124, ha defendido la teoría de que, en algunos casos, el empleo de diferentes nomina en los hijos podría deberse a que estos habrían nacido de un matrimonio anterior de la madre. Hay otros ejemplos de hijos de un matrimonio precedente que calificaron como pater al segundo marido de su madre, que no era su progenitor biológico. Igualmente, existen casos en los que ellos fueron calificados como filii por parte de sus padrastros. Véase, por ejemplo, $A E$ 1972, 273; $A E$ 1928, 166. En otras ocasiones, es difícil saber si hay un vínculo biológico entre padres e hijos o si, en realidad, estamos ante un padrastro y la descendencia de su esposa. Esa duda puede ser planteada en el caso de CIL II 3128.

92 CIL II $4412\left(=\right.$ RIT $683=$ HEp 2, 1990, 676). Testimonio $\mathrm{n}^{\mathrm{o}} 25$ del anexo.

93 CIL II 392. Testimonio $\mathrm{n}^{\circ} 26$ del anexo.
} 
muerto con tan solo cinco años, fue recordado por sus padres, Vibius Zoticus y Val(eria) Sponde, en una tumba de Italica. ${ }^{94}$ En este último caso, a juzgar por los cognomina empleados, estamos ante una familia de libertos en la que cada uno fue manumitido por diferentes personas.

\subsection{Los descendientes de los contubernia}

Las uniones estables entre esclavos, o entre esclavos y libres, eran denominadas contubernia y tampoco fueron reconocidas por el Derecho Romano. ${ }^{95}$ Los servi no podían disfrutar del ius connubii, requisito necesario para contraer unas iustae nuptiae, por lo que sus relaciones no eran consideradas legítimas. ${ }^{96}$ Por lo tanto, los hijos procreados en el seno de un contubernium eran ilegítimos y adquirían la condición jurídica de la madre. ${ }^{97}$ De este modo, si ella era esclava, la descendencia nacida de la misma era propiedad del dominus materno.

El liberto Aur(elius) Macedo es un ejemplo de hijo nacido durante la esclavitud de sus padres. ${ }^{98}$ Fue honrado con una inscripción funeraria que fue costeada por sus progenitores en Tarraco. Su padre, Marcianus, era un liberto imperial y mantenía un contubernium con Daphne. De esta última solamente conocemos el cognomen, por lo que no sabemos si ella había conseguido ya la libertad en el momento del fallecimiento de su hijo.

Hay casos en los que los padres eran manumitidos, pero sus hijos seguían siendo esclavos. Callaecio fue un servus que murió con veintitrés años de edad en Olisipo Felicitas Iulia. ${ }^{99}$ Los dedicantes del epitafio fueron sus progenitores, Lucretius Callaecus y Lucretia Maura. Estos últimos ya habían sido liberados cuando se realizó el texto; por lo tanto, Callaecio había nacido cuando su madre era una serva y, en consecuencia, adquirió esa misma condición jurídica desde el momento de su alumbramiento. Ella había conseguido la libertad con el paso del tiempo, al igual que el padre, mientras que el hijo falleció aún en la esclavitud. El hecho de que parte de la familia fuese libre no suponía siempre una separación, ya que los libertos seguían manteniendo una serie de obligaciones con los patronos e, incluso, muchos continuaban ejerciendo los mismos oficios que desempeñaban anteriormente.

En otras ocasiones, los padres eran esclavos y sus hijos eran libres. Un servus público llamado Hermia recordó a su vástago con un epitafio en la ciudad de Valeria ${ }^{100}$ su nombre era Ael(ius) Hermeros y fue un auriga que murió a los veintitrés años en Ilici. Las victorias y los premios obtenidos en las carreras, quizás, habrían facilitado la manumisión de Hermeros que, con toda probabilidad, fue esclavo desde su nacimiento al ser fruto de un contubernium. No obstante, desconocemos la identidad de su madre.

\footnotetext{
CIL II 1157 (=CILA 2, $488=$ ERIt 154). Testimonio $\mathrm{n}^{\circ} 27$ del anexo.

Baudry 1887.

Hay que destacar la afirmación: cum servis nullum est conubium (Ulp. Tit. ex corp. 5.5). Véase también Bonfante 1963, 190; Rawson 1974, 281-282; Treggiari 1981b, 43; Gardner 1986, 31; Evans Grubbs 1993, 127; Friedl 1996, 75; Pérez Negre 1998, 138-139; Rubiera Cancelas 2014, 69; Cantarella 2015, 91.

97 Gai. 1.82; Pérez Negre 1998, 139; Evans Grubbs 2002, 155; Cantarella 2015, 28, 38-39.

98 CIL II 4182 (=RIT 246). Testimonio $\mathrm{n}^{\circ} 34$ del anexo.

$99 \quad F E 293$ (=HEp 10, 2000, $730=A E 2000,683=A E 2001,1127)$. Testimonio $\mathrm{n}^{\mathrm{o}} 35$ del anexo.

100 CIL II 3181 (=CLE 123). Testimonio no 36 del anexo.
} 
Hay otros testimonios en los que todos los familiares habían conseguido la libertad después de un pasado servil. El liberto M. Calpurniu[s] Vernio y la liberta [C]alpurnia Thyce tuvieron cuatro vástagos que nacieron durante sus años de esclavitud: Calpurnia Nebris, Calpurnia Phyramis, [C]alpurnia Vitalis y $M$. Calpurnius Chrysero[s]. ${ }^{101}$ Todos ellos habían sido manumitidos, tal y como refleja su onomástica, y aparecen en el epitafio familiar que Blattia Modesta, segunda esposa de Vernio, encargó realizar en Ituci Virtus Iulia. ${ }^{102}$

En Barcino, el liberto L. Domitius Corinthus mandó colocar un epitafio para su familia. ${ }^{103}$ Junto a su esposa, Domitia Primula, incluyó los nombres de sus cinco hijos: Domitius Primulus, Domitius Florentinus, Domitius Pyramus, Domitius Phoebus y Domitius Picentinus. Todos ellos no eran solamente sus descendientes, sino que, al mismo tiempo, eran sus propios libertos. Pueden formularse varias hipótesis para explicar esta situación. En primer lugar, está claro que todos los hijos nacieron durante la esclavitud de sus progenitores, o al menos cuando su madre era una serva. No obstante, ambos ya eran libres en el momento en el que se realizó la inscripción. Pero, ¿cómo podían ser liberti idem filii? Una posibilidad era que L. Domitius Corinthus habría conseguido la libertad y podría haber comprado a su propia compañera sentimental, Primula. De este modo, él se habría convertido en su dominus y los hijos nacidos de esta unión serían esclavos de su padre. Por lo tanto, ella debió ser primero la serva de Corinthus para pasar a ser después su liberta et uxor tras la manumisión. ${ }^{104}$ Otra posibilidad consiste en considerar que tanto Corinthus como Primula habrían mantenido un contubernium durante la esclavitud y, tras ser liberados, él habría comprado a sus propios hijos esclavos para liberarlos posteriormente. La manumisión de toda la familia al mismo tiempo no siempre resultaba fácil ya que dependía de la voluntad del dominus.

En otros casos, sin embargo, todos los miembros de la familia son esclavos y así aparecen mencionados en el texto. Un testimonio de ello lo encontramos en una inscripción de Barcino que alude al servus Censorinus, ${ }^{105}$ quien había nacido del contubernium formado por Eucharis y Asellus. Otro ejemplo de este tipo lo hallamos en la familia de Euhodia, una verna de Augusta Emerita; ${ }^{106}$ sus padres, Euhodius y Callityche, tenían la condición servil y costearon una inscripción funeraria dedicada a su hija fallecida a los quince años de edad.

Igualmente, se atestigua la existencia de hijos que tuvieron padres de diversa condición social. Ese es el caso de Baebia Placida, una filia ilegítima documentada en Barcino. ${ }^{107} \mathrm{Su}$ padre era un ingenuus llamado P. Antonius Pudens y era originario de la ciudad de Lixus, situada en el norte de África. El texto indica que su madre, Baebia Novella, era una liberta. El hecho de que no se mencione si Baebia Placida era liberta puede indicar que había nacido tras la manumisión de su madre. No obstante, la hija había venido al mundo en el seno de una unión desigual que, por algún motivo, no era legítima en el momento del parto. Por lo tanto, a ella se le impuso el nomen materno. Otra explicación es que Baebia Placida hubiese nacido durante la esclavitud de su madre, por lo que ambas habrían pertenecido a la familia de los

$101 \quad C I L \mathrm{II}^{2} / 5,424(=H E p 8,1998,150)$. Testimonio $\mathrm{n}^{\circ} 37 \mathrm{del}$ anexo.

102 Solin 1982, 170-172, 444-446, 1063-1064, 1169. Kajanto 1965, 274, 314.

103 CIL II 4564 (=IRC IV, 157). Testimonio $\mathrm{n}^{\circ} 38$ del anexo.

104 Sobre las libertae et uxores, véase Cidoncha Redondo 2018, 363-392.

$105 \quad I R C$ IV, 320 (=HEp 12, 2002, $28=A E$ 2002, 860). Testimonio $\mathrm{n}^{\circ} 39$ del anexo.

$106 \quad E R A E 269(=A E$ 1982, 485). Testimonio n 40 del anexo.

107 CIL II 6157 (=IRC IV, 137). Testimonio $\mathrm{n}^{\circ} 41$ del anexo. 
Baebii y habrían sido manumitidas antes de realizarse esta inscripción funeraria. Posteriormente, tras el fallecimiento de Baebia Novella, el padre se unió a otra mujer llamada Cornelia Phaenusa. La madrastra de Placida también fue enterrada junto a ellas. Así, vemos cómo Pudens había buscado una nueva compañera sentimental al quedarse viudo, costumbre bastante habitual en la época. ${ }^{108}$

Hay ocasiones en las que se indica en el texto la condición de verna de algunos de estos individuos. Se consideraba que ellos eran los más fieles dentro del mundo servil porque habían nacido siendo esclavos y, frecuentemente, eran tratados mejor que otros de sus compañeros de esclavitud. ${ }^{109}$ Se ha detectado un importante número de vernae en la Hispania romana. ${ }^{110} \mathrm{~A}$ veces, aparecen en inscripciones junto a sus padres. Así se documenta en el monumento funerario colocado a L. Sulpicius Maxentius en Tarraco; ${ }^{111}$ L. Oppius Maximus fue el encargado de costear el epitafio para su hijo verna y para su coniux, Paedania Crescentina. Cada uno de ellos pertenecía a diferentes familias como muestran sus nomina, aunque esto no habría sido un impedimento para que siguieran unidos y fueran manumitidos cada uno por un dominus diferente.

\section{Conclusiones}

Los testimonios recogidos en este trabajo nos presentan a familias que se comportaban como el resto de la sociedad a pesar de que, en la mayoría de las ocasiones, las uniones que las conformaban no eran reconocidas por el Derecho Romano. Hemos visto cómo, por lo general, los hijos ilegítimos eran tratados igual desde el punto de vista social que aquellos engendrados en un iustum matrimonium. Las diferencias eran más marcadas en el ámbito jurídico, ya que eran excluidos de la posibilidad de ser nombrados herederos de su progenitor y solamente podían ser beneficiarios de legados testamentarios. Igualmente, tenían más dificultades para acceder a los cargos de la administración pública.

Los casos analizados en las fuentes epigráficas no siempre hacen referencias directas a la condición de filii naturales. No obstante, la onomástica nos aporta datos para reconocer la ilegitimidad de algunos de ellos. Así, la descendencia de estas relaciones adquiría el nomen materno, ya que no existía un padre desde el punto de vista jurídico. Los hijos naturales son fácilmente detectables en los epígrafes en los que aparecen siendo recordados por sus progenitores. Muchos casos se corresponden con esta descripción y podemos localizarlos gracias a la onomástica, ya que no siguen los patrones normales de la descendencia legítima. En otras ocasiones, el pasado servil, el desempeño de un determinado oficio por parte de sus padres, el tipo de unión de pareja que mantenían los mismos o la utilización de expresiones tales como filius, -a naturalis o $S p($ uri) f(ilius, -a) nos indican la condición de estos vástagos.

108 La mortalidad femenina a edades tempranas era alta debido, entre otros factores, a las condiciones higiénicas y sanitarias que provocaban que muchas de ellas fallecieran en los meses de gestación, durante el parto y en las semanas posteriores al alumbramiento. En ocasiones, la finalidad de estas segundas uniones era la búsqueda de una nueva madre para los hijos que habían quedado huérfanos. Sobre este tema, véase a Pomeroy 1990, 192.

109 Rawson 1986b, 186; Rubiera Cancelas 2014, 98.

110 Un importante estudio es el llevado a cabo por Crespo Ortiz de Zárate 2003. Rawson (1986b, 178-179) ha propuesto que, en algunos casos, los alumni podrían haber sido también hijos ilegítimos.

$111 \quad C I L$ II $4325\left(=C I L I^{2} / 14,1294=\right.$ RIT 371). Testimonio ${ }^{\circ} 42$ del anexo. 
En definitiva, esta muestra significativa representa una pequeña parte del verdadero número de hijos ilegítimos que habría en la sociedad hispanorromana. Dentro este grupo hay una gran variedad de testimonios que nos presentan individuos de estratos sociales humildes; no obstante, nos encontramos con algunos hijos, frecuentemente libertos, que pudieron prosperar y ascendieron desde los sectores más bajos de la escala social. Estamos ante una sociedad mixta e híbrida en la que no siempre predominaban los matrimonia iusta, sino que había diversos tipos de uniones de pareja, muchas de ellas ilegítimas a los ojos del Derecho Romano. A pesar de esto, la mayoría de ellas intentaron imitar y comportarse siguiendo los patrones del modelo romano de familia tradicional, incluso cuando no cumplían con algunas de sus características más significativas.

\section{Anexo de testimonios estudiados}

\subsection{Utilización de la expresión $S p(u r i) f(i l i u s,-a)$ en la filiación}

1. Epitafio familiar costeado por L. Valerius Rufinus: IRC IV, 221 (=HEp 7, 1997, 187). L(ucius) Valerius L(uci) f(ilius) An(iensis) / Rufinus sibi et / Corneliae Sp(uri) fil(iae) / Homullae cont(ubernali) / Cornelio Sp(uri) f(ilio) (H)ispano / Cornelio Sp(uri) f(ilio) Marcello / H(oc) m(onumentum) h(eredem) n(on) s(equetur) n(ec) l(ocus) s(epulturae).

2. Epitafio familiar costeado por $Q$. Cornelius Secundus: IRC IV, $59(=A E$ 1966, $207=A E$ 1993, $1746=$ HEp 7, 1997, $208=A E$ 2008, $761=$ Navarro Caballero 2017, 466).

[Q(uintus) Co]rnelius Sp(uri) f(ilius) Sec[undus] / d[o]mo colonia Ca[rtha]/gine Magna sibi et Corne[liae] / Quartae matri Gem(i)niae Q[uar]/tae uxori Corneliae Tertull[ae] I f(iliae) Q(uinto) Corn(elio) Seran(o)f(ilio) aed(ili) IIvi[ro] / Corn(eliae) Quartull(ae) f(iliae) Cor(neliae) Dubit[atae] / f(iliae) Cor(neliae) Sp(uri)f(iliae) Tertull(ae) sorori / L(ucio) Mae[vio] / Rogato sobrino.

3. Epitafio múltiple encargado por Servilia Fausta: ERAE 368. M(arco) Servilio M(arci) f(ilio) Pap(iria) / Pompeiae L(uci) l(ibertae) Helenae / M(arco) Servilio Tertio / M(arco) Servilio Sp(uri)f(ilio) Pollioni / Servilia M(arci) l(iberta) Fausta fecit.

4. Epitafio de Atilia Lucilla: CIL II 4457 (=IRC II, $18=$ HEp 6, 1996, $635=$ AE 1997, 924). Atiliae / Spuri f(iliae) / Lucillae / M(arcus) Antonius / [In]achus uxori.

\subsection{Casos en los que se documenta el uso de la expresión filius, -a naturalis}

5. Epitafio familiar de los Septicii: CIL II ${ }^{2} / 7,288$ (=AE 1987, $505=H E p$ 2, 1990, $324=H E p$ 5, 1995, 319).

M(arcus) Septicius C(ai)f(ilius) Pap(iria) / aquilifer sibi et Sabi[n]ae / contubernali suae et M(arco) Septicio / M(arci) lib(erto) Martiali filio naturali an(norum) X/ et mens(i)um VII / h(ic) s(iti) s(unt) s(it) v(obis) t(erra) l(evis) / post eorum obitum / hoc monimentum herede [m] / non sequetur. 
6. Epitafio de C. Atenius Acutus y su familia: CIL II 1213 (=CILA 2, 103).

C(aius) Atenius Acutus / ex testamento / sibi et Optatae / et Tertiae filiae / naturali.

7. Epitafio de Otacilia Serana: CIL II $2 / 14,266$ (=IRPV $49=$ AE 1984, 603).

D(is) M(anibus) / Otacil(iae) Seran(a)e / ann(orum) XVIII / Otacil(ius) Seranus / filiae naturali / et Otac(ilia) Chryso/polis filiae / pientissimae / h(ic) s(itae).

\subsection{Casos analizados por el empleo de la onomástica}

8. Epitafio de Allia Avita: CLEH 78 (=AE 1975, 483).

D(is) M(anibus) s(acrum) / Alliae Avit(a)e / an(norum) XXIII Vale/rius Ursacius / pater et Allia / [Ruf]ina mater / filiae pientissi/m(a)e f(aciendum) c(uraverunt) / d[ic] rogo qui / transis [sit] / tibi terra / levis.

9. Epitafio de Asellia Hygia y M. Publicius Felix: HEp 2, 1990, 37.

Asellia Hygia an(norum) XXXIX M(arcus) Publicius Felix / amantissimi h(ic) s(iti) s(unt) s(it) v(obis) t(erra) [l(evis)] / [ex testamen] to matri et patri et Asell(ia) [Cl]audia fil(ia) piiss(ima).

10. Epitafio de Plotia Saturnina: CIL II $2 / 14,1638$ (=RIT 639).

Have praesidi / D(is) M(anibus) / Plotiae Saturninae anno[r(um)] / XXVIII m(ensium) VIIII d(ierum) XIII Aelius Mel/pon coniugi optimae et deside/rantissimae cum qua vixit an(nos) XII / m(enses) V d(ies) VIII et Plotia Iucunda filia matri / dulcissimae b(ene) $m$ (erenti) fecerunt.

11. Epitafio de Numisia Ursula: CIL II 6172 (=IRC IV, $196=$ HEp 5, 1995, 128).

D(is) M(anibus) / Numisiae Ursulae / Aelius Cestinus / maritus et / Numisius Cestus fil(ius).

12. Epitafio de Valerius Melippus: CIL II 6178 (=IRC IV, 219).

D(is) M(anibus) / Valerio Melippo / Caelia Quar/tula fecit pat/ri cupa(m) bene / mer(enti) et Caelia / Saturnina / uxor m(arito) o(ptimo).

13. Epitafio de Baebius Senecianus: CIL II²/14, 649 (=CIL II $3972=$ ELST 305).

D(is) M(anibus) / Baebio Seneciano / annorum XVIII / Sergius Ursio et / Baeb(ia) Marcia / filio pientissi/mo et sibi fec[e]r(unt).

14. Epitafio de Fabia Prisca: CIL II 971 (=ERBC $209=$ HEp 7, 1997, 1152).

D(is) M(anibus) s(acrum) / Fabia Prisca / Serpensis c(ivis) R(omana) / ann(orum) XX h(ic) s(ita) e(st) s(it) t(ibi) t(erra) l(evis) / C(aius) Geminius Pris/cus pater et / Fabia Cadilla ma/ter posuerunt.

15. Epitafio de Aelius Primianus y de Caecilius Primianus: CIL II 4558 (=IRC IV, 141). D(is) M(anibus) / Aelio Primi/ano Caecil(ia) / Daphinis / marito ka/riss[i]mo et / Caec(ilio) Prim[i]/ano fil(io) / dulcissi/mo.

16. Epitafio de L. Annius Abascantus y de Terentia Annia: IRPLe 94 (=ERPLe $114=$ ENAR 49). 
D(is) M(anibus) / L(ucio) Annio / Abascanto / an(norum) LX et Te/rentiae An/niae f(iliae) an(norum) XIIX / Terentia Ap [ra] / marito et filiae.

17. Epitafio de Minicia Chreste: CIL II 3085 (=HEp 2, 1990, $680=$ IRPTo 21). D(is) M(anibus) s(acrum) / Miniciae / Chreste/ni ann(orum) LIX / Vitalis mar(itus) / et M(inicius) Chrestu(s) / fil(ius) f(aciendum) c(uraverunt) h(ic) [si(ta] e(st) s(it) t(ibi) t(erra) l(evis).

18. Epitafio de L. Maecius Scepticus y su familia: HEp 7, 1997, 121 (=AE 1999, 875). L(ucius) Maecius Scepti/cus ann(orum) LXXX/Laberia Daphne / uxor ann(orum) LX[--c] um qua vixit / annis LII L(ucius) La[be]rius Anti/gonus utror[um]que filius / ann(orum) LXX f(aciendum) c(uravit) h(ic) [s(iti)] s(unt) s(it) v(obis) t(erra) l(evis) / Cornelia Valentina ann(orum) X[X]XII h(ic) s(ita) e(st) / s(it) t(ibi) t(erra) l(evis).

19. Pedestal de Domitia Quartilla: CIL II 4359 (=RIT $459=$ CIL II ${ }^{2} / 14,1332=$ Navarro Caballero 2017, 345).

Domitiae / Quartillae / fil(iae) piissimae / M(arcus) Iulius Paris et / Domitia Musa / parentes et / L(ucius) [Do]mit(ius) Theseus / f(ilius) dulcissimus / matri.

20. Epitafio de Probus: $C I L \mathrm{II}^{2} / 7,363$ (=AE 1971, $179=$ EAOR VII, 25).

Mur(millo) |(contra)r(ete) / Probus / Pavil LXXXXIX / natione Germa(nus) / h(ic) s(itus) e(st) s(it) t(ibi) t(erra) l(evis) / Volumnia Spera[ta] / coniugi pio / merenti / P(ublius) Volumnius / Vitalis patri pio / s(it) t(ibi) t(erra) l(evis).

21. Epitafio de Flavia Rufina: CIL II 941 (=CPILC 658).

Flavia Rufina Augustobrig(ensis) / ann(orum) XXIIII h(ic) s(ita) e(st) s(it) t(ibi) t(erra) l(evis) / par(entes) Honorina et / C(aius) Rustenus Decianus filiae fec(erunt).

22. Epitafio de Marcius Faustus: CIRG I, 54 (=HEp 4, 1994, 352).

D(is) M(anibus) s(acrum) / M[a]rcius Faus(tus) an(norum) LXVII et / Cant(ia) Karia / an(norum) LV Ant(onius) / Modestus / parentibus / pientissimis.

23. Epitafio de Iulia Alba y Claudius Gracilis: HEp 19, 2010, 51 (=HEp 20, 2011, $15=$ AE 2010, 674).

D(is) [M(anibus)] s(acrum) / Cl(audio) Graci[li m]il(iti) leg(ionis) VII G(eminae) F(elicis) et / Iuliae Alb[a]e matri Aurelia Anna / parentib(us) pientissimis f(ecit) h(ic) s(itus) est TI.

24. Epitafio de Q. Baebius Florus: CIL II 516 (=EE VIII, 2, p. $362=$ ERAE 189). D(is) M(anibus) s(acrum) / Q(uintus) Baebius Florus / Gal(eria) Pacensi[s] / ann(orum) XXh(ic) s(itus) e(st) s(it) t(ibi) t(erra) l(evis) / P(ublius) Iul(ius) Hermetion pater / et Iulia Pitne mater / filio piissimo / et optimo fecer(unt).

25. Epitafio de Valeria Modestina: CIL II 4412 (=RIT $683=$ HEp 2, 1990, 676). Memoriae / Valeriae / Modestinae / quae vixit an(nos) / XXIIII m(enses) III d(ies) XXVII / Caecil(ius) / Polychronius / et Aurelia / Primitiva / filiae / karissimae. 
26. Epitafio de Valerius Rufinus: CIL II 392.

D(is) M(anibus) / Valeri / Rufini / ann(orum) XXIII / Turan(i)us / Primitivus / et Liberia / Stercusia / parentes fil(io) / piissimo / p(osuerunt).

27. Epitafio de M. Ulpius Heuretus: CIL II 1157 (=CILA 2, $488=$ ERIt 154). $D$ (is) M(anibus) s(acrum) / M(arco) Ulpio Heureto in/fanti suavissimo qui / vix(it) annis V mens(ibus) II / Vibius Zoticus et Val(eria) / Sponde par(entes) fil(io) dulcis(simo).

28. Epitafio de L. Valerius Severus: CIL II 4172 (=RIT $\left.225=C I L \mathrm{II}^{2} / 14,1086\right)$. L(ucio) Valerio / Severo / veterano leg(ionis) VII / G(eminae) F(elicis) C(aius) Iulius / Severus patri / pientissimo.

29. Epitafio de L. Popilius Prunicus: CIL II²/14, 1645 (=RIT 645). D(is) M(anibus) / L(ucius) Popilius / Prunicus / an(norum) XXV h(ic) s(itus) e(st) / G(aius!) Cornelius / Primigenius pater.

30. Epitafio de L. Clodius Barbarius: IRCP 254.

$D$ (is) M(anibus) s(acrum) / L(ucius) Clodius Barbario / an(nos) L v(ixit) h(ic) s(itus) e(st) s(it) t(ibi) t(erra) l(evis) / L(ucius) Iul(ius) Herennianus / fil(ius) patri piissimo f(aciendum) c(uravit).

31. Epitafio de Caius Caenonis y Claudia Casina: EFRBI 22.

Caio Caenonis / f(ilio) et Cl(audiae) Casinae / Cl(audius) Severus / patri et matri / $f$ (aciendum) c(uravit).

32. Epitafio de Claudius Reburrus: CIL II 5769 (=EE VIII, 2, p. $409=$ IRPP 85). D(is) M(anibus) s(acrum) / Cl(audio) Reburro / L(ucius) Cassius Reb(urrus) / p(atri) f(ilius) f(aciendum) c(uravit).

33. Epitafio de Flavius Onesimus: CIL II $2 / 14,1559$ (=RIT 580). $D($ is) M(anibus) / Flavio Onesimo an[no]/ro(m) L marito indul[gen]/tissimo et incompa[rabi]/li Flavia Cleopa[tra] / et Fonteia Melit[ine] / filia eius bene mere[nti] / feceru(n)t sit tibi t[er]/ra levis.

\subsection{Casos en los que se documentan descendientes de contubernia}

34. Epitafio de Aurelius Macedo: CIL II 4182 (=RIT $246=$ CIL II²/14, 1105) D(is) M(anibus) / Aur(eli) Macedonis lib(erti) / Marcianus Aug(usti) lib(ertus) / et Daphne parentes.

35. Epitafio de Callaecio: FE 293 (=HEp 10, 2000, $730=$ AE 2000, 683 = AE 2001, 1127). D(is) M(anibus) / Callaecioni / Lucreti Lupi ser(vo) an(norum) XXII[I] / Lucretius Callaecus / et Lucretia Maura / f(ilio) pientissimo f(aciendum) c(uraverunt).

36. Epitafio de Aelius Hermeros: CIL II 3181 (=CLE 123).

D(is) M(anibus) s(acrum) / Ael(io) Herme/roti aurig(a)e / defuncto / [Ili]ci ann(orum) XXIII / Hermia s(ervus) / r(ei) p(ublicae) Val(eriensis) / [fili]o in/conpara/bili s(it) t(ibi) 
t(erra) l(evis) / frequens viator / saepe qui transis lege / natus pro te sum / [---]ST[---] IOI[---]CO[---].

37. Epitafio familiar de los Calpurnii: $C I L \mathrm{II}^{2} / 5,424$ (=HEp 8, 1998, 150).

M(arcus) Calpurniu[s ---] / Vernio Augustalis / [C]alpurnia M(arci) l(iberta) Thyce uxor / Calpurnia M(arci) l(iberta) Nebris f(ilia) / M(arcus) Calpurnius M(arci) l(ibertus) Chrysero[s f(ilius)] / Calpurnia M(arci) l(iberta) Phyramis f(ilia) / [C]alpurnia M(arci) l(iberta) Vitalis f(ilia) / Blattia Modesta uxor f(ecit).

38. Epitafio familiar de los Domitii: CIL II 4564 (=IRC IV, 157).

L(ucius) Domitius L(uci) l(ibertus) / Corinthus sibi et / Domitiae Primulae / uxori et Domitis Primulo / Florentino Pyramo Phoe/bo Picentino lib(ertis) isdem fil(iis).

39. Epitafio de Censorinus y Asellus: IRC IV, 320 (=HEp 12, 2002, $28=$ AE 2002, 860). D(is) M(anibus) / Censorino / filio et / Asello con/tubernali / Eucharis.

40. Epitafio de Euhodia: ERAE 269 (=AE 1982, 485).

D(is) M(anibus) s(acrum) / Euhodia Mellini / verna an(norum) XV/h(ic) s(ita) e(st) s(it) t(ibi) t(erra) l(evis) / Euhodius et Ca/llityche f(iliae) pientis(s)umae.

41. Epitafio de la familia de P. Antonius Pudens: CIL II 6157 (=IRC IV, 137).

P(ublius) Antonius P(ubli) f(ilius) Pudens Lixita/nus sibi et / Baebiae T(iti) l(ibertae) Novellae uxori Baebiae Placidae f(iliae) / et Corneliae Phaenusae uxori / h(oc) m(onumentum) h(eredem) n(on) s(equetur) n(ec) l(ocus) s(epulturae).

42. Epitafio de L. Sulpicius Maxentius y Paedania Crescentina: CIL II 4325 (=RIT $371=$ CIL $\left.\mathrm{II}^{2} / 14,1294\right)$.

D(is) M(anibus) / L(ucio) Sulpicio / Maxentio / vern(ae) Tarrac(onensi) / L(ucius) Oppius Maximus / fil(io) et Paedania(e) / Crescentina(e) coniug(i) / b(ene) m(erentibus) f(ecit).

\section{Referencias bibliográficas}

Abascal, J. M. - Alföldy, G. (2015): Inscripciones romanas de la provincia de Toledo (siglos I-III), (=Real Academia de la Historia. Bibliotheca Archaeologica Hispana 42), Madrid $(=I R P T o)$.

Alföldy, G.

(1975): Die Römischen Inschriften von Tarraco (=Madrider Forschungen 10), Berlin (=RIT) (https://dx.doi.org/10.2307/503672).

(1984): "Epigraphica Hispanica V”, Zeitschrift für Papyrologie und Epigraphik 54, 221245.

Alföldy, G. - Clauss, M. - Mayer, M. (1995): Corpus Inscriptionum Latinarum II: Inscriptiones Hispaniae Latinae, ed. altera, pars XIV, fasciculus I. Pars meridionalis conventus Tarraconensis, Berlin-New York (=CIL II/2/14).

Álvaro Bernal, M. (2018): "La división de roles en la infancia: puellae educadas para el matrimonio", [en] P. Pavón (ed.), Marginación y mujer en el Imperio romano (siglos I-III), Roma, 103-132. 
Arends Olsen, L. (1999): La femme et l'enfant dans les unions illégitimes à Rome. L'évolution du droit jusqu'au début de l'Empire (=Publications Universitaires Européennes. Série 2, Droit 2714), Bern-Berlin-Bruxelles-Frankfurt-New York-Wien.

Astolfi, R.

(1996): La Lex Iulia et Papia, Modena.

(2006): Il matrimonio nel diritto romano classico, Padova.

Baudry, F. (1887): “Contubernales, contubernium”, [en] DAGR I (C), 1488-1489.

Beltrami, L. (1998): Il sangue degli antenati. Stirpe, adulterio e figli senza padre nella cultura romana (=Scrinia 9), Bari.

Beltrán Lloris, F. (1980): Epigrafia latina de Saguntum y su territorium (=Serie de Trabajos Varios 67), Valencia (=ELST).

Biondi, B. (1943): Trattato di Diritto Romano 9-10: Successione testamentaria, donazioni, Milano.

Bonfante, P. (1963): Corso di diritto romano. Volume primo: Diritto di famiglia, Milano (reed. G. Bonfante - G. Crifò).

Bücheler, F. - Lommatzsch, E. (1930): Carmina Latina Epigraphica, Leipzig (=CLE).

Buongiorno, P. (2010): Senatus consulta Claudianis temporibus facta. Una palingenesi delle deliberazioni senatorie dell'età di Claudio (41-54 d.C.), Napoli.

Campbell, J. B. (1978): "The marriage of soldiers under the empire", Journal of Roman Studies 68, 153-166 (http://dx.doi.org/10.2307/299633).

Cantarella, E. (2015): Istituzioni di diritto romano, Firenze.

(2016): "Women and Patriarchy in Roman Law", [en] P. J. du Plessis - C. Ando - K. Tuori (eds.), The Oxford Handbook of Roman Law and Society, Oxford, 419-431 (http:// dx.doi.org/10.1093/oxfordhb/9780198728689.013.32).

Canto, A. M.

(1985): La epigrafía romana de Itálica, Madrid (=ERIt).

(1997): Epigrafía Romana de la Beturia céltica (=UAM Ediciones. Colección de Estudios 54), Madrid (=ERBC).

Castán Pérez-Gómez, S. (2000): "El concubinato en la experiencia jurídica romana", [en] J. M. Castán Vázquez - C. Guzmán Pérez - T. M. Pérez-Agua López - J. M. Sánchez García (coords.), Hominum causa omne ius constitutum est. Escritos sobre el matrimonio en homenaje al Prof. Dr. José María Díaz Moreno, S.J. (=Universidad Pontificia de Comillas, Serie IV, Homenajes 2), Madrid, 1459-1477.

Cenerini, F. (2002): La donna romana. Modelli e realtà, Bologna.

Centlivres Challet, C. E. (2013): Like Man, Like Woman. Roman Women, Gender Qualities and Conjugal Relationships at the Turn of the First Century, Bern.

Cherry, D. (1990): "The Minician Law: Marriage and the Roman Citizenship", Phoenix 44/3, 244-266 (http://dx.doi.org/10.2307/1088935).

Cidoncha Redondo, F.

(2017): "Los gladiadores, sus mujeres e hijos en las provincias occidentales del Imperio Romano", Antesteria 6, 133-147.

(2018): "Libertae et coniuges: las uniones entre libertas y patronos en el Imperio Romano", [en] P. Pavón (ed.), Marginación y mujer en el Imperio romano (siglos I-III), Roma, 363392.

Corbett, P. E. (1930): The Roman Law of Marriage, Oxford.

Corell, J.

(1996): Inscripcions Romanes d'Edeta i el seu territori, Valencia (=IRET). 
(1999): Inscripcions Romanes d'Ilici, Lucentum, Allon, Dianium i els seus territoris, Valencia (=IRILAD)

(2005): Inscripcions romanes del País Valencià II: 1. L'Alt Palància Edeba, Lasera i els seus territoris ( $=$ Fonts històriques valencianes 12,52$)$, Valencia (=IRPV II).

(2008): Inscripcions Romanes d'Edeta i el seu territori (=Fonts històriques valencianes 37), Valencia $\left(=I R E T^{2}\right)$.

Crespo Ortiz de Zárate, S. (2003): Verna en Hispania Romana, Valladolid.

Cugusi, P. (2012): Carmina Latina Epigraphica Hispanica post Buechelerianam collectionem editam reperta cognita (=Epigrafia e Antichità 31$)$, Faenza $(=C L E H)$.

Curchin, L. A.

(2000): "Problems with Children's Nomenclature in Roman Spain", [en] J. Alvar (ed.), Homenaje a José Ma Blázquez IV. Hispania Romana I (=ARYS 2), Madrid, 121138.

(2000-2001): “The Roman Family: Recent Interpretations”, Zephyrus 53-54, 535-550.

D’Ambra, E. (2007): Roman women, Cambridge.

Diego Santos, F. (1986): Inscripciones Romanas de la Provincia de León, León (=IRPLe).

D’Ors, A. (2006 [1968]): Derecho privado romano, Pamplona.

Edmondson, J. (2001): "Conmemoración funeraria y contexto social", [en] J. Edmondson - T. Nogales Basarrate - W. Trillmich, Imagen y memoria: monumentos funerarios con retratos en la colonia Augusta Emerita (=Real Academia de la Historia. Bibliotheca Archaeologica Hispana 10, Monografías Emeritenses 6), Madrid.

Encarnação, J. d' (1984): Inscrições Romanas do Conventus Pacensis: subsidios para o estudo da romanização, vol. 1, Coimbra $(=I R C P)$.

Evans Grubbs, J.

(1993): "Marriage More Shameful Than Adultery: Slave-Mistress Relationships, Mixed Marriages and Late Roman Law", Phoenix 47/2, 125-154 (http://dx. doi. org/10.2307/1088581).

(1995): Law and Family in Late Antiquity: The Emperor Constantine's Marriage Legislation, Oxford.

(2002): Women and the Law in the Roman Empire. A sourcebook on marriage, divorce and widowhood, London-New York.

Fabre, G. (1976): "Les affranchis et la vie municipale dans le péninsule ibérique sous le Haut-Empire romain: quelques remarques", [en] Actes du colloque 1973 sur l'esclavage (=Annales Littéraires de l’Université de Besançon 182), Paris, 417-462.

Fabre, G. - Mayer, M. - Rodà de Llanza, I.

(1985): Inscriptions romaines de Catalogne II: Lérida, Paris (=IRC II).

(1997): Inscriptions romaines de Catalogne IV: Barcino, Paris (=IRC IV).

Fayer, C. (2005): La familia romana. Parte terza: Concubinato, Divorzio, Adulterio (=Problemi e ricerche di storia antica 22), Roma.

Fernández Vizcaíno, B. (2011): "El ius adscrescendi en la regulación de los senadosconsultos Tertuliano y Orficiano", Revista Internacional de Derecho Romano 7, 518-591.

Ferreira, A. P. R. (2004): Epigrafia funerária romana da Beira Interior. Inovação ou continuidade? (=Trabalhos de Arqueologia 34), Lisboa (=EFRBI).

Flores Santamaría, P. (1986): "Las jóvenes romanas: una educación para el matrimonio" [en] E. Garrido González (ed.), La mujer en el mundo antiguo. Actas de las V Jornadas de Investigación Interdisciplinaria, Madrid.

Friedl, R. (1996): Der Konkubinat im kaiserzeitlichen Rom von Augustus bis Septimius Severus, Stuttgart. 
Galinsky, K. (1981): “Augustus' Legislation on Morals and Marriage”, Philologus 125, 126144 (https://dx.doi.org/10.1524/phil.1981.125.12.126).

García Iglesias, L. (1973): Epigrafía Romana de Augusta Emerita, Madrid (=ERAE).

García Moreno, L. A. (1986): "Sobre el decreto de Paulo Emilio y la Turris Lascutana", [en] Epigrafía hispánica de época romano-republicana (Zaragoza, 1-3 de diciembre de 1983), (=Publicaciones de la Institución "Fernando el Católico" 1066), Zaragoza, 195-218.

Gardner, J. F.

(1986): Women in Roman Law and Society, London.

(1989): "The Adoption of the Roman Freedman", Phoenix 43, 236-257 (https://dx.doi. org/10.2307/1088460).

(1997): "Legal Stumbling-Blocks for Lower-Class Families in Rome", [en] B. Rawson - P. Weaver (eds.), The Roman Family in Italy: status, sentiment, space, Oxford, 35-53.

Garnsey, P. (1991): “Child rearing in ancient Italy”, [en] D. I. Kertzer - R. P. Saller (eds.), The family in Italy from antiquity to the present, New Haven, 48-65.

Gómez-Pantoja, J. L. (2009): Epigrafia anfiteatrale dell'Occidente Romano VII: Baetica, Tarraconensis, Lusitania (=Vetera 17), Roma (=EAOR VII).

González Fernández, J.

(1986): J. González Fernández, "The Lex Irnitana: a New Copy of the Flavian Municipal Law", Journal of Roman Studies 76, 147-243 (https://dx.doi.org/10.2307/300371).

(1991): Corpus de Inscripciones Latinas de Andalucia II: Sevilla I: La Vega (Hispalis), Sevilla (=CILA 2).

González Fernández, R. - Fernández-Ardanaz, S. (2010): “Algunas cuestiones en torno a la promulgación de la Constitutio Antoniniana”, Gerión 28/1, 157-192.

Hernández Guerra, L. (1994): Inscripciones romanas en la provincia de Palencia (=Historia y Sociedad 39), Valladolid (=IRPP).

Herreros González, C. - Santapau Pastor, M. C. (2005): "Prostitución y matrimonio en Roma: ¿uniones de hecho o de derecho?”, Iberia 8, 89-111.

Hübner, A. (1869): Corpus Inscriptionum Latinarum II. Inscriptiones Hispaniae Latinae, Berlin (=CIL II).

Humbert, M. (1976): “Libertas id est civitas, Autour d'un conflit négatif de citoyennetés au II, s. avant J.-C.”, MEFRA 88/1, 221-242 (https://doi.org/10.3406/mefr.1976.1056).

Hurtado San Antonio, R. (1977): Corpus Provincial de Inscripciones Latinas de Cáceres, Cáceres (=CPILC).

Kajanto, I. (1965): The Latin Cognomina (=Commentationes Humanarum Litterarum 2), Helsinki.

Lécrivan, Ch. (1887): “Spurii”, [en] DAGR IV (R-S), 1445-1446.

Lemosse, M. (1975): “L'Enfant sans famille en droit romain”, [en] L'enfant, première partie: Antiquité, Afrique, Asie (=Societé Jean Bodin. Recueils 35), Brussels, 257-270.

Leonard, P. (1900): “Concubinatus”, [en] RE Pauly-Wissowa, t. IV/1, 835-388.

López Melero, R. (1991): “Observaciones sobre la condición de los primeros colonos de Carteia", Studia Historica. Historia Antigua 9, 43-50.

Luchetti, G. (1990): La legitimazione dei figli naturali nelle fonti tardo imperiali et giustinianee, Milano.

Mañanes Pérez, T. (1982): Epigrafía y numismática de Astorga romana y su entorno (=Acta Salmanticensia. Filosofía y Letras 134), Salamanca (=ENAR).

Marcos Pous, A. (1987): "Inscripción cordobesa de un aquilifer", [en] VV.AA., Archivo de Prehistoria Levantina XVII. Homenaje a D. Domingo Fletcher Valls, t. I, Valencia, 367382. 
Mariner Bigorra, S. (1973): Inscripciones romanas de Barcelona, Barcelona (=IRB).

Martínez López, C. (1999): "Y parirás hijos para gloria de Roma. Las mujeres y la ciudadanía en la Roma Antigua”, [en] M. Ortega López - C. Sánchez Muñoz - C. Valiente Fernández (eds.), Género y ciudadania: revisiones desde el ámbito privado. XII Jornadas de Investigación Interdisciplinaria, Madrid, 143-162.

Masi Doria, C.

(2000): "In margine a PS. 2.21a.11", [en] M. Zabłocka - W. Wołodkiewicz (eds.), Audelà des frontiers: Mélanges de droit romain offerts a Witold Wołodkiewicz 1, Varsovia, 507-519.

(2013): “Ancilla efficitu... in eo statu manebit: le conseguenze del SC. Claudianum per le donne di status libertino", [en] Rodríguez López - Bravo Bosch (eds.), 2013, 157-178.

McGinn, T. A. J. (1991): "Concubinage and the Lex Iulia on adultery", Transactions of the American Philological Association 121, 335-375 (https://dx.doi.org/10.2307/284457).

McWilliam, J. (2001): "Children among the dead. The influence of urban life on the commemoration of children on tombstone inscriptions", [en] S. Dixon (ed.), Childhood, Class and Kin in the Roman World, London, 74-98.

Meyer, P. (1966 [1895]): Der römische Konkubinat nach den Rechtsquellen und den Inschriften, Aalen.

Navarro Caballero, M. (2017): Perfectissima femina. Femmes de l'élite dans l'Hispanie romaine (=Ausonius Éditions. Scripta Antiqua 101), Bordeaux, 2 vols.

Ordóñez Agulla, S. (1988): Colonia Augusta Firma Astigi, Écija.

Pavón Torrejón, P. (2016): "La mujer en la legislación de Adriano", Studia et Documenta Historiae et Iuris 82, 265-290.

Pena, M J J. (2014): "El gentilicio Canuleius y la fundación de la colonia latina de Carteia", Epigraphica 76/1-2, 146-164.

Perea Yébenes, S. (1993): "El Aquilifer M. Septicius en una inscripción de Córdoba", Habis 24, 297-306.

Pereira Menaut, G. (1991): Corpus de Inscricións Romanas de Galicia I: Provincia de A Coruña, Santiago de Compostela (=CIRG I).

Pérez Negre, J. (1998): "Esclavas, semilibres y libertas en época imperial: aspectos sociojurídicos", [en] C. Alfaro Giner - A. Noguera Borel (eds.), Actas del Primer Seminario de Estudios sobre la Mujer en la Antigüedad (Valencia, 24-25 de abril de 1997), Valencia, 137-159.

Pomeroy, S. B. (1990): Diosas, rameras, esposas y esclavas. Mujeres en la Antigüedad Clásica (=Akal Universitaria Interdisciplinar 104), Madrid.

Quadrato, R. (1969): "I senatoconsulti Tertulliano e Orfiziano", Labeo 15, 362-377.

Rabanal Alonso, M. A. - García Martínez, S. Ma (2001): Epigrafía romana de la provincia de León: revisión y actualización, León $(=E R P L e)$.

Raditsa, L. F. (1980): “Augustus’ Legislation Concerning Marriage, Procreation, Love Affairs and Adultery", Aufstieg und Niedergang der römischen Welt 2/13, 278-339.

Rawson, B.

(1966): "Family Life among the Lower Classes at Rome in the First Two Centuries of the Empire", Classical Philology 61/2, 71-83 (http://dx.doi.org/10.1086/365094).

(1974): "Concubinage and other de facto marriages", Transactions of the American Philological Association 104, 279-305 (http://dx.doi.org/10.2307/2936094).

(1986a): "The Roman Family", [en] Rawson (ed.), 1986, 1-57.

(1986b): "Children in the Roman Familia", [en] Rawson (ed.), 1986, 170-200.

Rawson, B. (ed.), (1986): The Family in Ancient Rome: New Perspectives, London-Sidney. 
Robert, J.-N. (1986): Les plaisirs a Rome (=Les Belles Lettres. Realia 2), Paris.

Rodríguez Adrados, J. V. (1986): "Sistema onomástico de la mujer en el mundo romano", [en] E. Garrido González (ed.), La mujer en el mundo antiguo. Actas de las V Jornadas de Investigación Interdisciplinaria, Madrid, 205-215.

Rodríguez López, R. - Bravo Bosch, Mª J. (eds.), (2013): Mulier. Algunas Historias e Instituciones de Derecho Romano, Madrid.

Rodríguez Oliva, P. (2006): "Unas inscripciones funerarias de Lacipo (Casares, Málaga) que evocan el establecimiento en Carteia (San Roque, Cádiz) de la Colonia Latina Libertinorum", Baetica 28, 123-157.

Rubiera Cancelas, C. (2014): La esclavitud femenina en la Roma antigua. Famulae, ancillae et seruae (=Colección Deméter 5), Oviedo.

Salazar Revuelta, M. (2013): "Estatus jurídico y social de la materfamilias en el marco de la ciudadanía romana”, [en] Rodríguez López - Bravo Bosch (eds.), 2013, 199-222.

Saumagne, Ch. (1962): "Une colonie latine d'affranchis: Carteia", Revue Historique de Droit Français et Étranger 40, 135-152.

Sirks, A. J. B. (2005): "Der Zweck des Senatus Consultum Claudianum von 52 n. Chr.", Zeitschrift der Savigny-Stiftung für Rechtsgeshichte 122, 138-149.

Solin, H.

(1973): "Namengebung und Epigraphik", [en] Akten des VI Internationalen Kongresses für Griechische und Lateinische Epigraphik, München, 404-407.

(1982): Die griechischen Personennamen in Rom: Ein Namenbuch, Berlin-New York.

Solin, H. - Salomies, O. (1988): Repertorium nominum gentilium et cognominum Latinorum, Hildesheim-Zürich-New York.

Spagnuolo Vigorita, T. (2010): Casta domus. Un seminario sulla legislazione matrimoniale augustea. Parte prima e seconda, Napoli.

Speidel, M. A. (2013): “Les femmes et la bureaucratie. Quelques réflexions sur l'interdiction du mariage dans l'armée romaine", Cahiers du Centre Gustav Glotz 24, 205-215 (https:// doi.org/10.3406/ccgg.2013.1802).

Stylow, A. U. - González Román, C. - Alföldy, G. (1995): Corpus Inscriptionum Latinarum II: Inscriptiones Hispaniae Latinae, ed. altera, pars VII. Conventus Cordubensis, BerlinNew York $\left(=C I L \mathrm{II}^{2} / 7\right)$.

Treggiari, S.

(1981a): “Concubinae", Papers of the British School at Rome 49, 59-81 (http://dx.doi. org/10.1017/S0068246200008473).

(1981b): “Contubernales in CIL 6", Phoenix 35/1, $42-69$ (http://dx.doi.org/10.2307/ 1087137).

(2002): Roman Marriage: iusti coniuges from the time of Cicero to the time of Ulpian, New York-Oxford.

Valmaña-Ochaíta, A. (2013): "La mujer romana en las relaciones de pareja”, [en] Rodríguez López - Bravo Bosch (eds.), 2013, 135-154.

Weaver, P. R. C. 1986: "The Status of Children in Mixed Marriages", [en] Rawson (ed.), 1986, 145-169.

Wells, C. M. (1998): “Celibate soldiers: Augustus and the army”, American Journal of Ancient History 14/2, 180-190 (http://dx.doi.org/10.31826/9781463237615-004).

Wulff Alonso, F. (1989): "La fundación de Carteya. Algunas notas", Studia Historica. Historia Antigua 7, 43-57. 